\title{
Macrocyclic Arenes Functionalized with BODIPY: Rising Stars among Chemosensors and Smart Materials
}

\author{
Jianjun Huang ${ }^{1}$, Yuyu Fang ${ }^{1,2, *}$ and Wim Dehaen ${ }^{1, *}$ \\ 1 Department of Chemistry, KU Leuven, Celestijnenlaan 200F-bus 02404, 3001 Leuven, Belgium; \\ jianjun.huang@kuleuven.be \\ 2 State Key Laboratory of Southwestern Chinese Medicine Resources, School of Pharmacy, \\ Chengdu University of Traditional Chinese Medicine, Chengdu 611137, China \\ * Correspondence: yyfang@cdutcm.edu.cn (Y.F.); wim.dehaen@kuleuven.be (W.D.)
}

Received: 13 June 2020; Accepted: 2 July 2020; Published: 6 July 2020

\begin{abstract}
Macrocycles play a crucial role in supramolecular chemistry and the family of macrocyclic arenes represents one of the most important types of hosts. Among them, calixarenes, resorcinarenes and pillararenes are the most commonly encountered macrocyclic arenes, and they have received considerable attention. Boron-dipyrromethene (BODIPY) dyes are fascinating compounds with multiple functionalization sites and outstanding luminescence properties including high fluorescence quantum yields, large molar absorption coefficients and remarkable photo- and chemical stability. The combination of macrocyclic arenes and BODIPY dyes has been demonstrated to be an effective strategy to construct chemosensors for various guests and smart materials with tailored properties. Herein, we firstly summarize the recent advances made so far in macrocyclic arenes substituted with BODIPY. This review only focuses on the three macrocyclic arenes of calixarenes, resorcinarenes and pillararenes, as there are no other macrocyclic arenes substituted BODIPY units at the present time. Hopefully, this review will not only afford a guide and useful information for those who are interested in developing novel chemosensors and smart materials, but also inspire new opportunities in this field.
\end{abstract}

Keywords: Calixarenes; resorcinarenes; pillararenes; BODIPY; chemosensors; smart materials

\section{Introduction}

In the course of the development of supramolecular chemistry, macrocycles play a crucial role as indicated by their innate characteristics of unique host-guest recognition properties [1]. Undoubtedly, the creation of a new class of synthetic macrocycles with versatile architectures offers unparalleled opportunities for chemists to explore novel supramolecular systems [2]. Functional groups mounted on readily available macrocycles, on the other hand, may endow the resulting functionalized compounds with anticipated chemical or physical properties, which has been widely demonstrated by their application including but not limited in host-guest chemistry, chemosensors, self-assembly systems, areas related to biology, and supramolecular smart materials. The successful examples include crown ethers [3], cyclodextrins [4], calixarenes [5], cavitands [6], cucurbiturils [7], as well as other macrocyclic systems [8-10]. Not surprisingly, considerable and continuous efforts have been devoted to this active research field.

Among the various macrocycles, the family of macrocyclic arenes represents one of the most important hosts in supramolecular chemistry [8,11-17]. Calixarenes, resorcinarenes, and pillararenes are the most commonly encountered macrocyclic arenes, and they have been widely investigated. Calixarenes, considered as the third generation of supramolecular hosts (crown ethers and cyclodextrins are the first and second generation of supramolecular macrocycles, respectively), are unique macrocycles 
consisting of phenolic units linked by methylene groups at the 2- and 6-positions (Figure 1a) [5]. The history of calixarenes could be traced back to Bayer's pioneering work on the reaction of one-pot phenol-formaldehyde condensation in 1872, but these macrocycles failed to receive extensive attention for a long period of time until Gutsche and coworkers determined the selective synthesis and exact structure of the different possible cyclic structures (particularly the cyclotetramer, cyclohexamer, and cyclooctamer) in the 1970s [18]. Since then, the chemistry of calixarenes has been developing rapidly not only due to the facile and tunable functionalization of their lower and/or upper rims, but also to the well-defined conformations that are both substituent- and guest-dependent. Benefiting from these distinctive advantages, calixarenes and their derivatives have been described as unique and interesting macrocycles, which have been used in a wide range of areas and well summarized in several excellent reviews [5,19-21].

Resorcinarenes [22], which can be easily obtained by $4+4$ acid-catalyzed condensation of resorcinol with certain aldehydes, are a class of macrocyclic arenes that are structurally close to calixarenes (Figure 1b). Particularly, resorcin[4] arenes are the major products under specific conditions and rigidification of their skeletons by bridging adjacent resorcinol units (usually methylene bridges, phosphorus atoms, or heterophenylene moieties) results in deep-cavity cavitands [23]. In many scenarios, the trivial name of cavitands is used to describe functionalized resorcin[4]arene-based hosts where an additional second row of rings has been introduced to the resorcin[4]arene backbone, leading to extend the cavity of these macrocycles with a bowl-shaped architecture. For example, resorcin[4]arene-based cavitands bridged by four quinoxaline or pyrazine moieties represent a fascinating family of macrocycles capable of adopting two spatially preferred conformations (a contracted vase and an expanded kite) with profound geometry and property differences [24]. As a result, resorcin[4]arene-based cavitands have been demonstrated to be an ideal platform for construction of molecular grippers [25], chemosensors [26], self-assembly systems [27], and so on [28-30].

In 2008, a new family of macrocycles, namely pillararenes, were first introduced by Ogoshi and co-workers [31]. Structurally, pillararenes are akin to calixarenes but differ in the repeating multi-hydroquinone units connected via methylene bridges at their para positions. There are at least three complementary strategies to synthesize pillararenes and pillar[5]arenes are the smallest members among the series under thermodynamically controlled conditions [32]. On the basis of their facile and versatile functionalization, unique and rigid pillar-shaped structures, and interesting host-guest properties, pillararenes have been attracting increasing attention over the past decade and are currently considered as key players in supramolecular chemistry [33]. Consequently, the potential applications of pillararenes in a wide range of fields have been well documented [34-41]. Recently, we have summarized pillararene-based receptors for selective metal ions binding and pillararene-based supramolecular self-assembly systems driven by metal-ligand coordination [42].

(a)

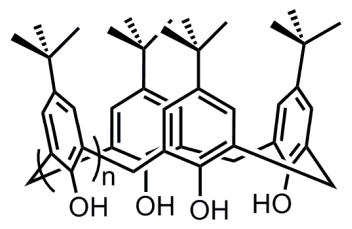

Calixarenes (b)

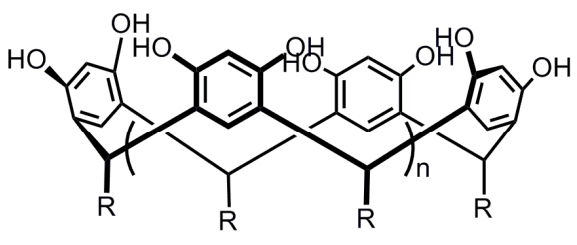

Resorcinarenes (c)

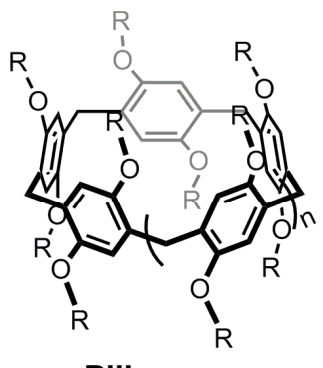

Figure 1. Chemical structures of three commonly encountered macrocyclic arenes: (a) calixarenes, (b) resorcinarenes, and (c) pillararenes.

Recently, the difluoroboron dipyrromethene (better known as the trademark BODIPY with its IUPAC name of 4-difluoro-4-bora-3a,4a-diaza-s-indacene, Figure 2a) dyes are fascinating compounds, which are the subject of active and prolific research due to their multiple functionalization sites 
and outstanding luminescence properties such as high fluorescence quantum yields, large molar absorption coefficients and remarkable photo- and chemical stability [43]. The first BODIPYs were reported as early as 1968 by Treibs and Kreuze [44]. However, not until the pioneering work of Boyer and coworkers in the early 1990s did the BODIPYs became a booming and successful research area [45]. Notably, even very small modifications on the BODIPY framework can lead to distinct fluorescence characteristics, and considerable amount of decoration usually occurs on the $\alpha_{-}^{-}, \beta-$, or meso-positions of BODIPY via alkylation, arylation, or halogenation. Our group has summarized the postfunctionalization methodologies together with the potential applications of BODIPYs and their analogues [46-49]. Meanwhile, several excellent reviews involved BODIPY dyes have been presented mainly focusing on the applications in fluorescent probes for ion sensing [46], $\mathrm{pH}$ indicators [50], neutral species [51], bioimaging [52,53], construction of electrochemical materials [54] and light harvesting systems [55], and so on [56-58] (Figure 2b). Their sensing mechanisms mainly include photo-induced electron transfer (PET), intramolecular charge transfer (ICT), excited-state intermolecular proton transfer (ESIPT), and metal-to-ligand charge transfer (MLCT). In addition, BODIPY units have been demonstrated to be potent building blocks to construct various BODIPY-based macrocycles (Figure 2c), where BODIPY moieties are introduced into the macrocyclic skeletons rather than act as the substituents [59-65]. Up until now, the research related to the combination of macrocyclic arenes and BODIPY dyes has not been systematically summarized.

(a)

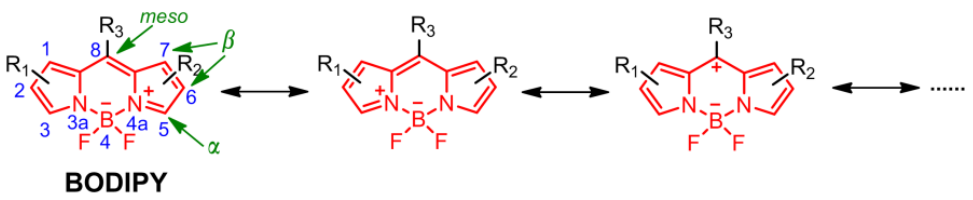

(b)

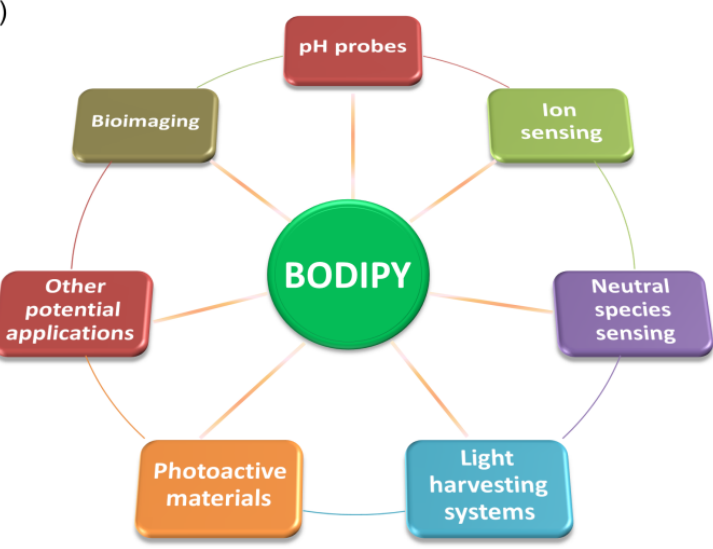

(c)

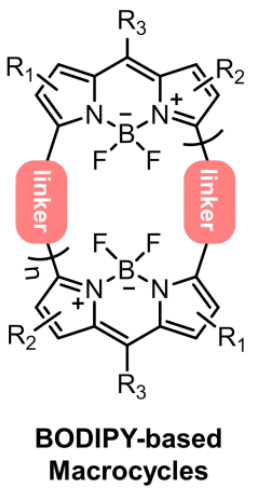

Figure 2. (a) Chemical structure of the boron-dipyrromethene (BODIPY) framework; (b) the potential applications of BODIPY derivatives; and (c) chemical structure of the BODIPY-based macrocycles.

In this mini-review, we summarized the progress made so far of macrocyclic arenes substituted with BODIPY and their attractive application in the construction of chemosensors and smart materials will be discussed in detail, according to the type of macrocyclic arene. In this text, we do not treat the macrocycles that incorporate BODIPY into their framework, but rather macrocyclic arenes substituted with the BODIPY fluorophore. Finally, the prospects and challenges related to the area will also be briefly introduced.

\section{Calixarenes with BODIPY Functionalities}

\section{1. s-Block Metal Ion Sensing}

Selective and sensitive detection of metal ions is essential due to their irreplaceable role in a myriad of biological processes. Nevertheless, a specific metal ion imbalance and/or potentially intrinsic toxicity 
may result in significant adverse impacts on both the environment and human health. Sensing of s-block cations, consisting of alkali and alkaline earth metal ions, is of particular interest since these cations play roles in osmotic regulation and generation of action potentials. Chang's group reported the synthesis and fluoroionophoric properties of calix[4]arene-crown-5 ether derivative 1 (Figure 3), which were functionalized with a BODIPY fluorophore at the upper rim for the signaling of $\mathrm{Ca}^{2+}[66]$. Compound 1, which was prepared from the corresponding calixcrown dialdehyde via acid-catalyzed condensation with 2,4-dimethylpyrrole followed by oxidation and boron chelation, showed an intense green fluorescence emission at $507 \mathrm{~nm}$ and a small shoulder around $545 \mathrm{~nm}$ in $\mathrm{CH}_{3} \mathrm{OH}$ upon irradiation at $480 \mathrm{~nm}$. The addition of $\mathrm{Ca}^{2+}$ led to a near-complete fluorescence quenching (390-fold) response in the presence of specific aliquots of $\mathrm{LiOH}$ (This compound was used to obtain the optimum $\mathrm{pH}$ condition), while the other metal ions $\left(\mathrm{Na}^{+}, \mathrm{K}^{+}\right.$, and $\left.\mathrm{Mg}^{2+}\right)$, showed almost no changes in the fluorescence spectrum in both intensity and position. This selective $\mathrm{Ca}^{2+}$ sensing mechanism could be ascribed to a photo-induced electron transfer (PET) process from the phenolate group to the BODIPY fluorophore. Notably, an increase in the ratio of water resulted in reduced selectivity of $\mathrm{Ca}^{2+}$ over other metal ions, from which an optimal solvent system of $\mathrm{MeOH}-\mathrm{H}_{2} \mathrm{O}(95: 5, v / v)$ was obtained for the practical application of chemosensor $\mathbf{1}$ for $\mathrm{Ca}^{2+}$. The binding constant and detection limit of $\mathbf{1}$ for $\mathrm{Ca}^{2+}$ in this mixed aqueous media was deduced to be $5.4 \times 10^{5} \mathrm{M}^{-1}$ and $2.0 \times 10^{-6} \mathrm{M}$, respectively.
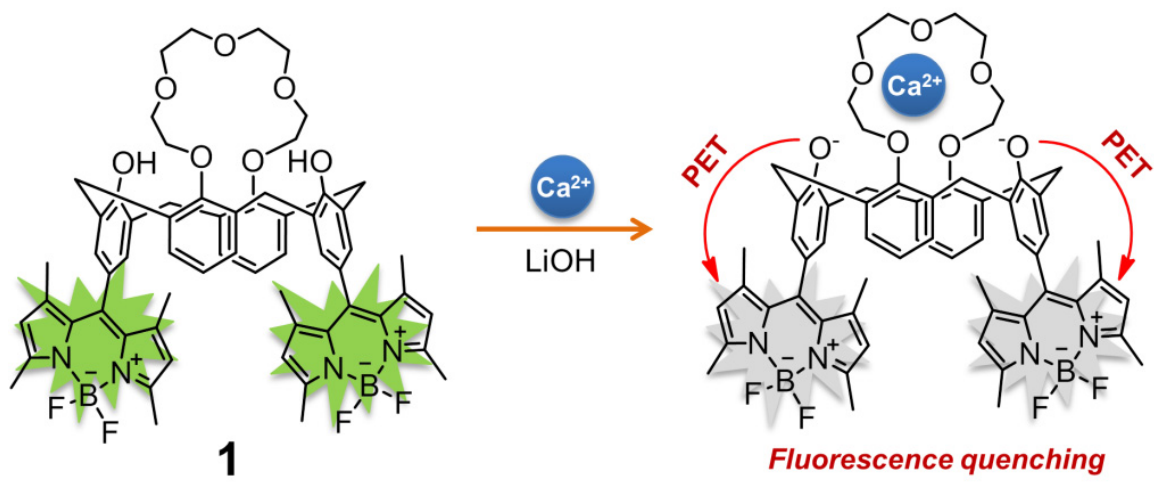

Figure 3. BODIPY-functionalized calix[4]arene $\mathbf{1}$ for $\mathrm{Ca}^{2+}$.

In 2006, Kim and coworker described a calix[4]arene-based chemosensor 2 functionalized with two BODIPY moieties in the upper rim and two ester groups at the lower rim for selective recognition of $\mathrm{Ca}^{2+}$ in acetonitrile solution (Figure 4) [67]. A dramatic fluorescence quenching at $506 \mathrm{~nm}$ was observed selectively upon addition of $\mathrm{Ca}^{2+}$, which could be attributed to the reverse PET mechanism that electron transfers occur from BODIPY unit to carbonyl group upon coordination with $\mathrm{Ca}^{2+}$. No distinctive absorbance change was observed of 2 for various metal cations. The binding constant of 2 and $\mathrm{Ca}^{2+}$ was determined to be $5.2 \times 10^{7} \mathrm{M}^{-1}$ with a stoichiometry of 1:1. In sharp contrast, the control compound 3, which contains tetraethyl ester groups on the lower rim, and the compound 4 without ester moiety both showed a very poor fluorescence response for $\mathrm{Ca}^{2+}$, highlighting the importance of the two distal hydroxyl groups and two facing ethyl esters on the selective recognition of $\mathrm{Ca}^{2+}$ via unique cooperative coordination.

Malval et al. developed a ditopic fluorescent chemosensor 5 for $\mathrm{K}^{+}$which included 1,3-alternate calix[4]bisazacrown-5 as an ionophore and substituted BODIPY dyes as the signaling units (Figure 5) [68]. Compound 5 was synthesized from 2,4-dimethylpyrrole and biscalixcrown, followed by oxidation with 2,3-dichloro-5,6-dicyano-1,4-benzoquinone (DDQ) and further chelation with boron trifluoride etherate in the presence of ethyldiisopropylamine. UV-vis spectrum of fluoroionophore 5 showed a narrow absorption peak at $500 \mathrm{~nm}$ and a sharp band around $260 \mathrm{~nm}$ which was not affected by the polarity of the solvent, whereas the fluorescence properties was strongly solvent-dependent. For example, the fluorescence quantum yield of compound 5 decreased from 0.27 to 0.003 as the polarity of the solvent increased from hexane to acetonitrile. Meanwhile, another emission band 
centered at $630 \mathrm{~nm}$ was observed in a medium polarity solvent like tetrahydrofuran, which was attributed to an efficient charge transfer (CT) in its excited state. The addition of trifluoroacetic acid (TFA) to an ethanol solution containing 5 resulted in the disappearance of the absorption band at $260 \mathrm{~nm}$ together with the fluorescence quantum yield increasing from 0.003 to 0.67 , probably due to the protonation of the amino group that efficiently blocked the CT process. Specifically, the fluorescence enhancement was more pronounced for $\mathrm{K}^{+}$(154-fold in ethanol) at higher cation concentrations owing to the formation of a bimetallic complex. Probe 5 exhibited a high sensitivity and selectivity for $\mathrm{K}^{+}$over other s-block metal ions $\left(\mathrm{Na}^{+}, \mathrm{Cs}^{+}, \mathrm{Ca}^{2+}\right.$, and $\mathrm{Ba}^{2+}$ ), as indicated by much higher binding constant of 5 for $\mathrm{K}^{+}$(at least three orders of magnitude higher than that for other s-block cations). In addition, the determination of $\mathrm{K}^{+}$based on the sensor 5 in extracellular conditions (serum or whole blood) was also achieved, demonstrating the excellent practical feasibility of this system for $\mathrm{K}^{+}$detection under physiological conditions.

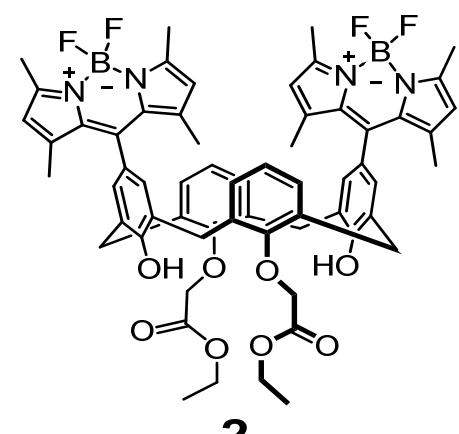

2

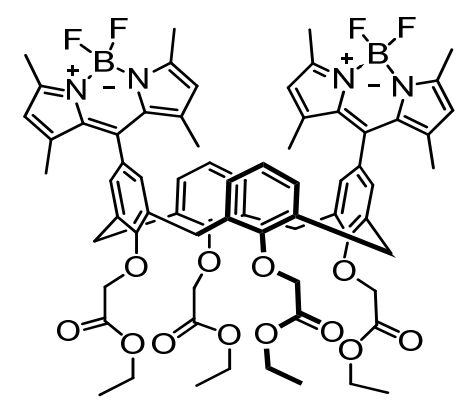

3

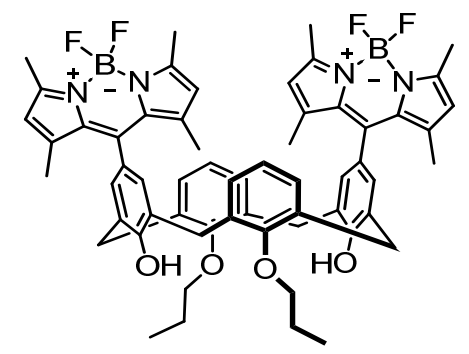

4

Figure 4. Chemical structures of calix[4]arene-based chemosensors $2-4$ for $\mathrm{Ca}^{2+}$.

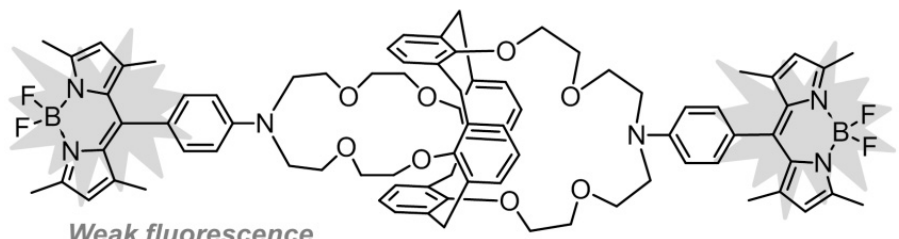

Weak fluorescence

5
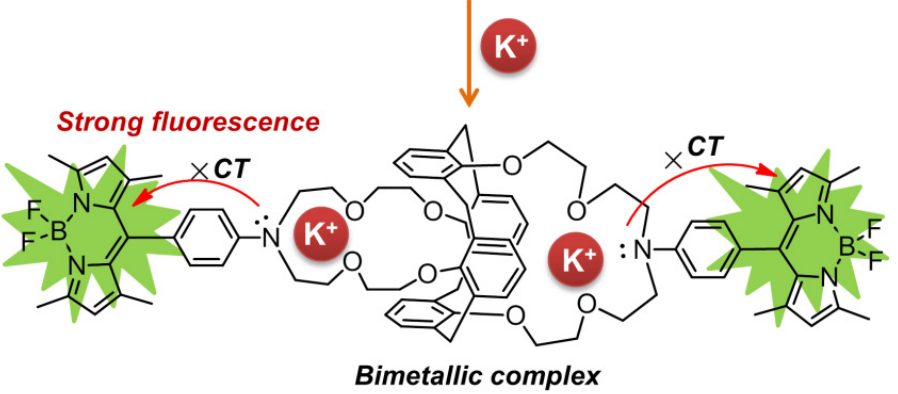

Figure 5. Ditopic fluorescent sensor 5 for sensitive and selective recognition of $\mathrm{K}^{+}$.

The detection of cesium cations is of great interest. The toxicity of cesium is known to be due to the replacement of potassium ions in muscles and red blood cells, leading to cardiac diseases and cancers [69]. Leray and coworkers reported the preparation of two novel 1,3-alternate calix[4]arene biscrown-6-ethers 6 and 7 appended with BODIPY moieties and their binding properties towards alkali metal ions of $\mathrm{K}^{+}$and $\mathrm{Cs}^{+}$(Figure 6) [70]. As confirmed by steady-state and time-resolved fluorescence experiments as well as theoretical calculations, the complexation with the two cations was closely related to the position of a substituted coordination site on the BODIPY unit. Thus, compound 7, decorated with the BODIPY at the meso-position showed no obvious spectral change for $\mathrm{K}^{+}$and $\mathrm{Cs}^{+}$ (as their $\mathrm{ClO}_{4}{ }^{-}$salts) in $\mathrm{CH}_{3} \mathrm{CN}$. In contrast, the addition of the two cations to $\mathrm{CH}_{3} \mathrm{CN}-\mathrm{CH}_{2} \mathrm{Cl}_{2}(9: 1$, 
$v / v$ ) containing 6 , which was tethered with two styryl linker at the $\alpha$-position of BODIPY backbone using a Knoevenagel-type condensation of the azacrown dialdehyde with dimethylBODIPY, resulted in a hypsochromic shift of the absorption and emission maximums. Both compounds had a better binding affinity towards $\mathrm{Cs}^{+}$than $\mathrm{K}^{+}$with 2:1 (metal:ligand) binding stoichiometries due to the good size complementarity between $\mathrm{Cs}^{+}$and the cavity of the crown ether.
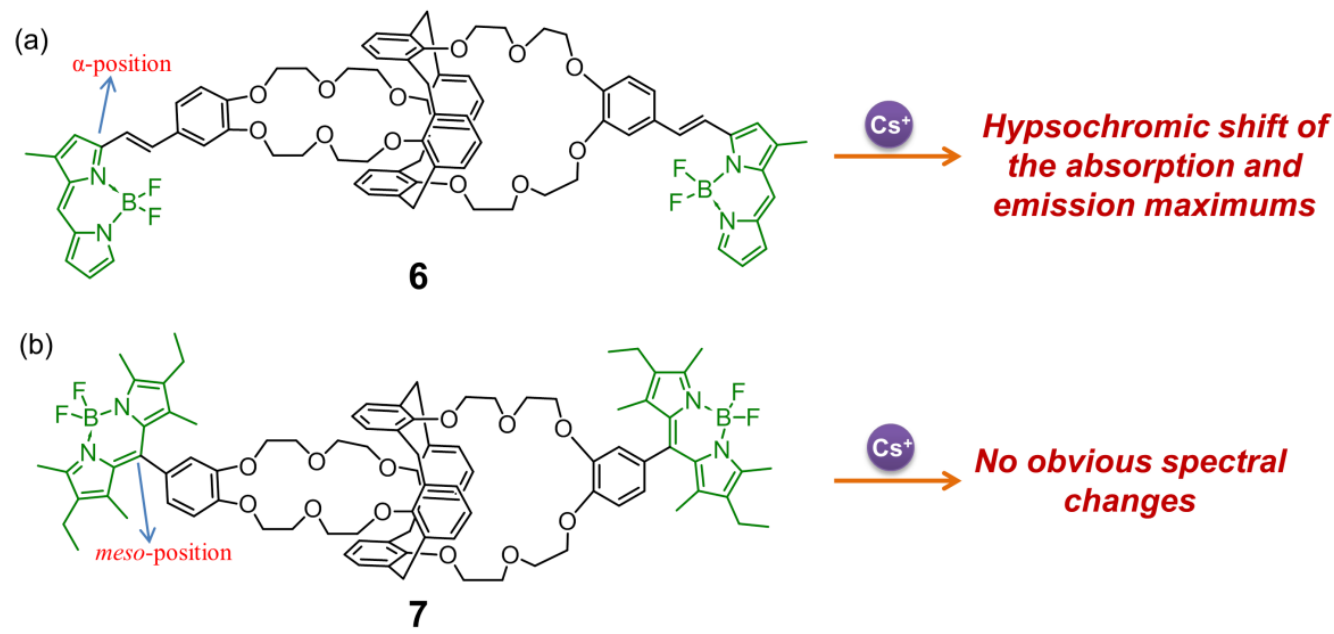

Figure 6. Structures of calix[4]arene-based probes (a) 6 and (b) 7.

\subsection{Transition Metal Ion Sensing}

Csokai et al. developed thiacalix[4](N-phenylazacrown-5) ether 8 functionalized with a BODIPY fluorophore moiety as a turn-on fluorescent chemosensor for certain transition metal ions (particularly $\mathrm{Cu}^{2+}$ ) in acetonitrile solution (Figure 7) [71]. Upon addition of 40 equivalents of mono- or divalent metal ions, $\mathrm{Cu}^{2+}$ and $\mathrm{Fe}^{3+}$ caused a slight red-shift of the maximum absorption band centred at $497 \mathrm{~nm}$, whilst an enhancement of the maximum absorbance together with an obvious red-shift (15-20 nm) were observed in the presence of $\mathrm{Hg}^{2+}$. On the other hand, the weak fluorescence emission spectrum of ligand 8 around $520 \mathrm{~nm}$ was dramatically enhanced (11.8-fold) upon treatment with 4.0 equivalents of $\mathrm{Cu}^{2+} . \mathrm{Hg}^{2+}$, and $\mathrm{Fe}^{3+}$ ions also induced fluorescence enhancement, but only to a much lesser extent with respect to $\mathrm{Cu}^{2+}$ even upon addition of 40 equivalents of 8 . The unique turn-on fluorescence for $\mathrm{Cu}^{2+}$-sensing could be ascribed to the inhibition of the PET process from the nitrogen of the azacrown ether to the BODIPY core and formation of a 1:1 $\mathrm{Cu}^{2+}-8$ complex with a binding constant of $\operatorname{logK}=4.40$, which could be further demonstrated by the distinct fluorescence enhancement of 8 upon protonation with TFA. Additionally, a plasticized PVC membrane constructed from probe 8 also showed marked potentiometric recognition of $\mathrm{Ag}^{+}$.

Selective recognition of specific lanthanide metal ions from the whole lanthanide series is extremely difficult due to the pronounced similarity in physical and chemical properties (e.g., identical +3 oxidation state and nearly similar ionic radii) deriving from the lanthanide contraction [72]. In 2013, M. Bayrakcı et al. reported a novel calixazacrown ether 9 appended with two BODIPY groups and two amide bridges on the narrow rim (Figure 8), which could act as an excellent fluorescent probe for the selective recognition of $\mathrm{Yb}^{3+}$ in methanol solution [73]. Compound 9 was synthesized by alkylation of the corresponding calix[4] arene (ethyl-eneamido)crown with 4-chloromethylphenyl BODIPY derivative. No distinguishable absorption changes of $\mathbf{9}$ were observed for six tested lanthanide ions including $\mathrm{La}^{3+}, \mathrm{Gd}^{3+}, \mathrm{Tb}^{3+}, \mathrm{Dy}^{3+}, \mathrm{Er}^{3+}$, and $\mathrm{Yb}^{3+}$. On the other hand, a highly selective recognition of $\mathrm{Yb}^{3+} \mathrm{was}^{3}$ achieved, indicative of the fluorescence enhancement of 9 at $530 \mathrm{~nm}$, which could be attributed to the suppression of the intramolecular PET process. Probe 9, possessing a symmetrical cone conformation, bound $\mathrm{Yb}^{3+}$ in a 1:1 stoichiometry.

It is well-known that mercury can cause harmful effects on both living organisms because of its high toxicitiy. As a result, facile and applicable detection of $\mathrm{Hg}^{2+}$ is important and necessary [74-76]. 
In 2017, Sulak et al. developed a calix[4]arene-based chemosensor 10 containing triazole-linked naphthalenes as the ionophore groups and BODIPY derivatives as the fluorescent signal units (Figure 9), which showed highly selective and sensitive fluorescence recognition of $\mathrm{Hg}^{2+}$ in $\mathrm{MeOH}-\mathrm{H}_{2} \mathrm{O}(v / v, 9: 1)$ media [77]. Compound 10 was obtained by the similar alkylation via 4-chloromethylphenyl BODIPY and corresponding calix[4]arene functionalized with two triazole-linked naphthalenes. The strong fluorescence emission of $\mathbf{1 0}$ centred at $575 \mathrm{~nm}$ was near-completely quenched in the presence of $\mathrm{Hg}^{2+}$, which was not liable to interference by twelve other tested transition metal ions. Meanwhile, the addition of $\mathrm{Hg}^{2+}$ also led to an observable blue shift of the absorption band. These emission and absorption changes were attributed to selective binding of $\mathrm{Hg}^{2+}$ with two triazole units, resulting in efficient energy transfer from the BODIPY-naphthyl excimer to $\mathrm{Hg}^{2+}$ and formation of a $\mathbf{1 0}-\mathrm{Hg}^{2+}$ complex in 1:1 stoichiometry. The binding constant and detection limit of $\mathbf{1 0}$ for $\mathrm{Hg}^{2+}$ was calculated to be $3.42 \times 10^{7} \mathrm{M}^{-1}$ and $2.80 \times 10^{-7} \mathrm{M}$, respectively.
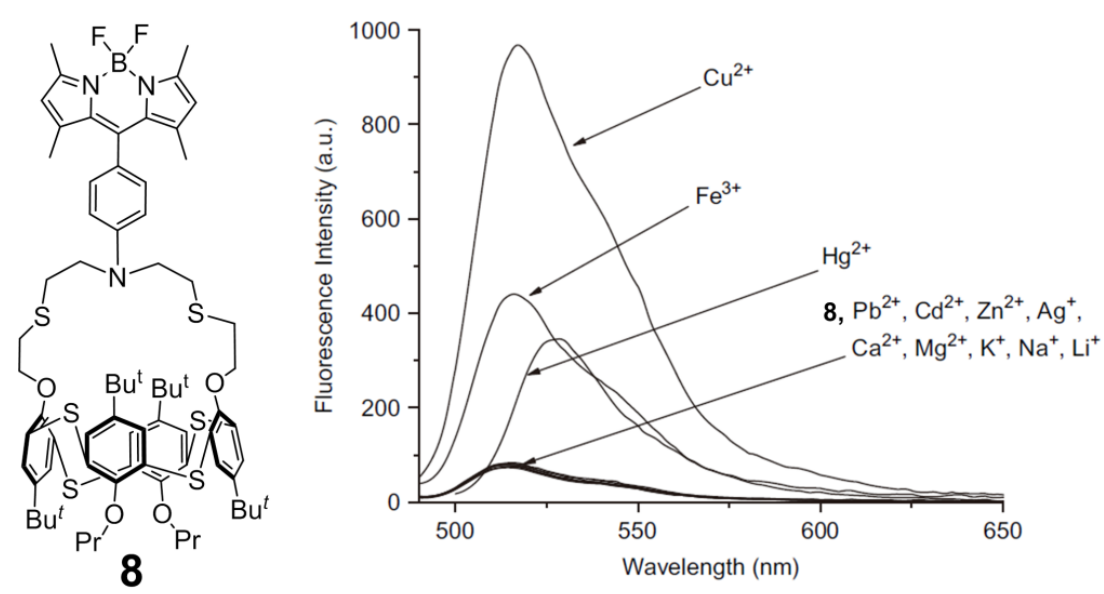

Figure 7. Chemical structure of thiacalix[4](N-phenylazacrown-5)ether $\mathbf{8}$ for selective recognition of $\mathrm{Cu}^{2+}$ in acetonitrile solution $\left(\mathrm{Cu}^{2+}: 4.0\right.$ equivalent, other metal cations: 40 equivalent). Reproduced with permission from Reference [71]. Copyright 2007 Elsevier.

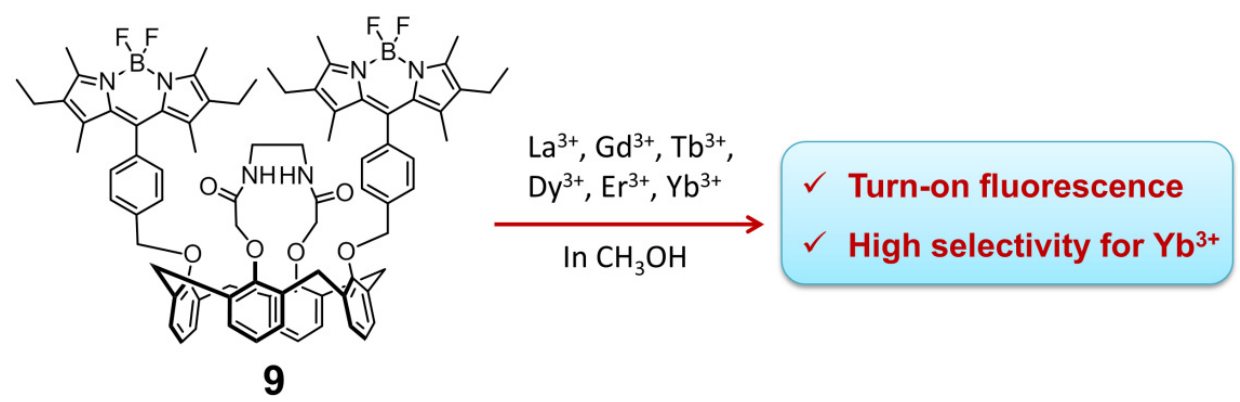

Figure 8. Chemical structure of calix[4]azacrown ether 9 appended with two BODIPY groups and two amide bridges.
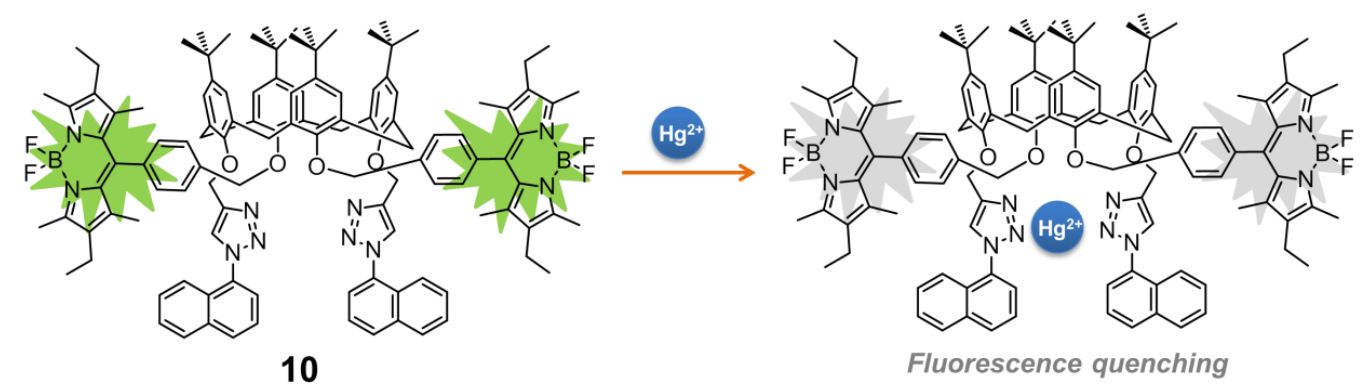

Figure 9. Chemical structure of calix[4]arene derived chemosensor $\mathbf{1 0}$ for the detection of $\mathrm{Hg}^{2+}$. 


\subsection{Fluorescence Sensing of $p H$}

The $\mathrm{pH}$ value is one of the most generally important chemical parameters. Particularly, intracellular $\mathrm{pH}$ plays a pivotal role in many biological processes and abnormal $\mathrm{pH}$ changes may lead to serious cellular dysfunction which is closely related to many diseases [78-81]. Akkaya and coworkers reported a novel upper-rim mono-BODIPY functionalized calix[4]arene 11 (Figure 10), which could sensitively detect $\mathrm{pH}$ changes in $\mathrm{EtOH}-\mathrm{H}_{2} \mathrm{O}(1: 1, v / v)$ solution [82]. The absorption spectrum of $\mathbf{1 1}$ centred at $490 \mathrm{~nm}$ was not affected by the change in $\mathrm{pH}$ values, whereas a remarkable emission quenching at $509 \mathrm{~nm}$ was observed upon increasing the $\mathrm{pH}$ value from 2.53 to 11.54 . The fluorescence signal was completely reversed by adjusting the $\mathrm{pH}$ values and the apparent $\mathrm{pK}_{\mathrm{a}}$ value was deduced to be 6.5. The first deprotonation was expected to be at the remote phenol unit with a $\mathrm{pK}_{\mathrm{a}}$ value of 4.5, while an efficient PET process only occurs when the adjacent phenol group was deprotonated at a slightly higher $\mathrm{pH}$. Subsequently, Qin's group demonstrated that compound $\mathbf{1 1}$ had excellent cell permeability and retention as well as minor cytotoxicity, which was further employed as a fluorescent probe for precise detection of intracellular $\mathrm{pH}$ values, particularly during early cell apoptosis [83]. Importantly, probe 11 represents the first example of a BODIPY-based probe for monitoring cytosolic $\mathrm{pH}$ changes. In addition, a plasticized polyvinyl chloride (PVC) film containing compound $\mathbf{1 1}$ and anion exchanger tridodecylmethylammonium chloride (TDMACl) was also fabricated [84], which can act as an optical sensor for simultaneous detection of four blood electrolytes including $\mathrm{Cl}^{-}, \mathrm{K}^{+}, \mathrm{Na}^{+}$, and $\mathrm{Ca}^{2+}$. The determined concentrations of the four electrolytes agreed very well with the results obtained by conventional potentiometric methods, suggesting its potential applications of the proposed fluorescent ion optodes in clinical diagnosis.

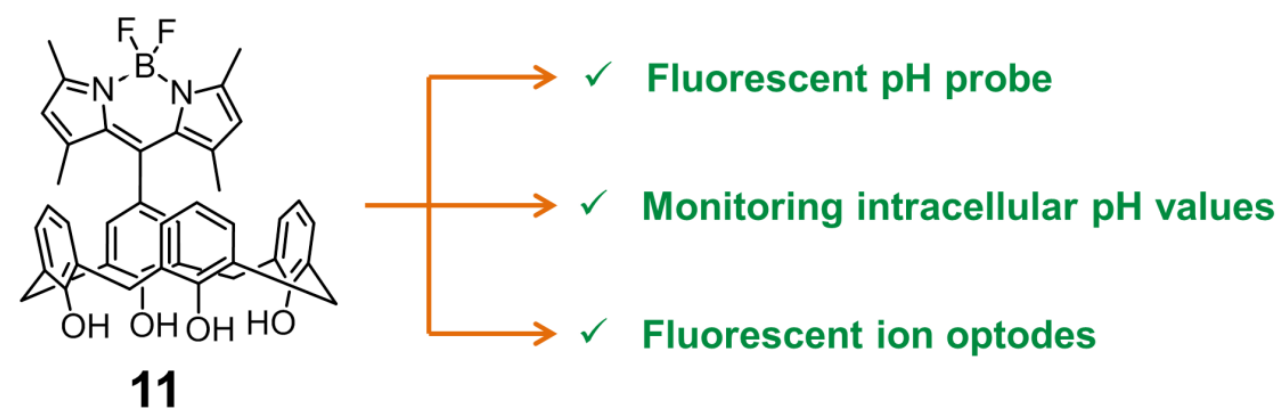

Figure 10. Chemical structures of mono-BODIPY functionalized calix[4]arene 11.

\subsection{Other Applications}

Photodynamic therapy (PDT) is a photochemical-based medical technique to treat various types of cancer and diseases, which involves the use of a combination of light source and a preferably nontoxic light-activated chemical (also called photosensitizer) [85]. Despite the limited biological activities of the photosensitizer, irradiation of a mixture of this compound and molecular oxygen by light at a specific wavelength promotes the formation of cytotoxic reactive oxygen species (ROS) including singlet oxygen $\left({ }^{1} \mathrm{O}_{2}\right)$, hydrogen peroxide $\left(\mathrm{H}_{2} \mathrm{O}_{2}\right)$, hydroxyl radicals $(\mathrm{OH} \cdot)$, and superoxide anions $\left(\mathrm{O}_{2} \cdot{ }^{-}\right)$, which are considered to be the principal mechanism for the destruction of target cells [85]. Notably, BODIPY dyes have also been regarded as ideal photosensitizers for PDT [86]. Cakmak et al. developed calix[4]arene 12 functionalized with two BODIPYs by Knoevenagel-type strategy (Figure 11), which can act as a photosensitizer with efficient intersystem crossing tendency owing to the presence of heavy iodine atoms located at the BODIPY backbone. The electronic absorption spectrum of compound 12 exhibited a strong and near infrared absorption peak at $725 \mathrm{~nm}$ with an extinction coefficient of $130,000 \mathrm{M}^{-1} \cdot \mathrm{cm}^{-1}$. The hydrophobicity of the long-chain alkyl substituents on the lower rim and the hydrophilicity originating from the two polyethylene glycol (PEG) groups on the end of upper rim endowed 12 with unique amphiphilic propertities. As a result, singlet oxygen could be efficiently 
generated in the presence of photosensitizer 12 and irradiation with light of $725 \mathrm{~nm}$ in both organic solvents and aqueous solutions, implying its potential application in enhanced PDT.

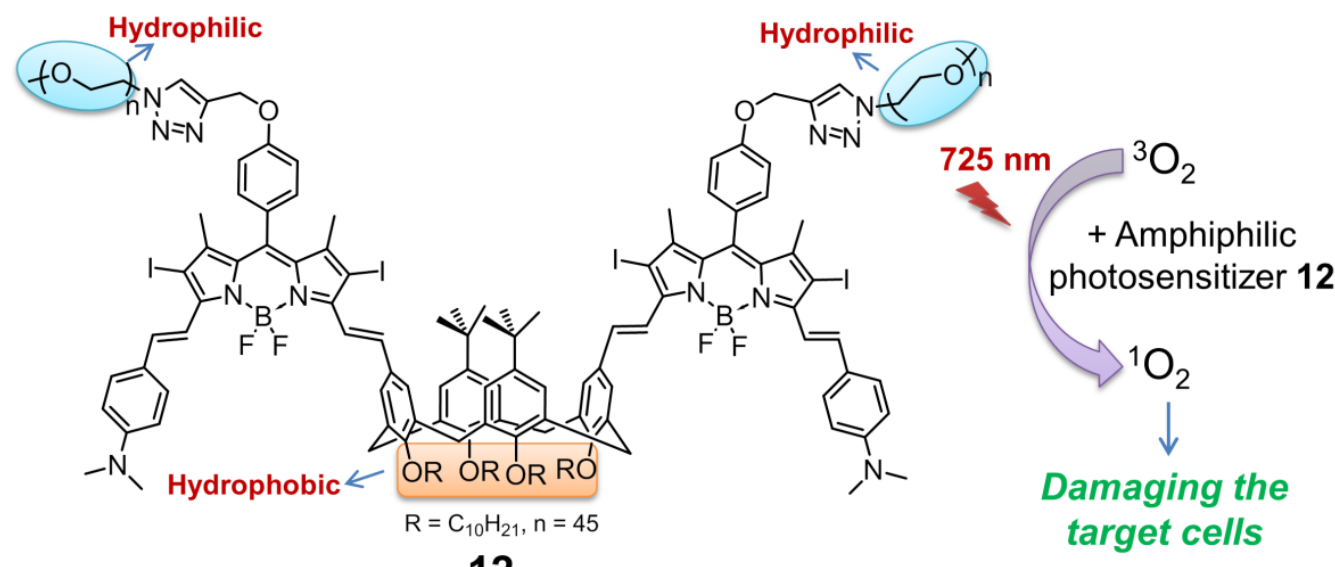

12

Figure 11. Chemical structure of BODIPY functionalized calix[4]arene $\mathbf{1 2 .}$

Tosi et al. reported the synthesis and electronic energy transfer (EET) behaviour of a novel calix[4]arene derivative 13 decorated with two different BODIPY chromophores (A and B) by Williamson alkylation on the distal positions of its upper rim (Figure 12) [87]. Given the good spectral overlap between fluorescence emission of BODIPY A (the energy donor) and the absorption of BODIPY B (the energy acceptor), an efficient EET between the two dyes was expected to occur, while the calix[4]arene scaffold was chosen to provide a good control of the mutual orientation and distance between two BODIPY chromophores. Steady-state spectroscopic characterization of $\mathbf{1 3}$ showed that the solvent polarity had only a negligible effect on the absorption, whereas its emission was solvatochromic, suggesting the presence of new non-radiative decay paths in the bichromophore. An efficient and fast energy transfer occurred in the bichromophore as shown by transient absorption measurements, indicating that kinetics were closely related to the polarity of the solvent (e.g., $7.5 \mathrm{ps}$ in acetonitrile, $25 \mathrm{ps}$ in chloroform). Highly polar media resulted in fast and efficient energy transfer, while the reverse energy transfer was significantly slowed down in non-polar media. Especially, the apparent dynamics of the energy transfer process in cyclohexane was slower by an order of magnitude as compared to polar solvents, which could be attributed to the backward energy transfer from BODIPY B to BODIPY A. By a combination of the results obtained from the steady-state and time-resolved spectroscopy and density functional theory (DFT)/time dependent-DFT (TD-DFT) calculations, the efficient EET of 13 was successfully demonstrated.

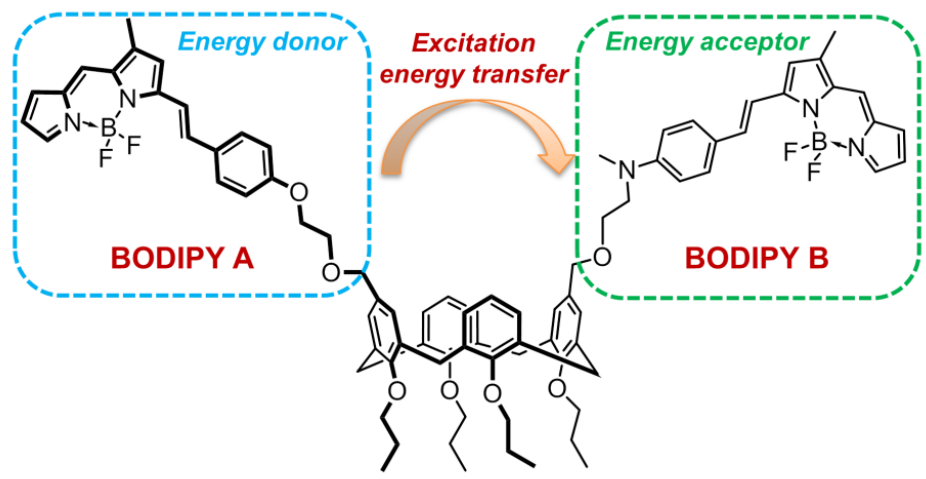

Figure 12. Chemical structure of calix[4]arene derivative 13 decorated with two different BODIPY chromophores. 


\section{Resorcinarenes Functionalized with BODIPY}

Among the various classes of cavitand molecules, the quinoxaline-bridged resorcin[4]arene 14 and its derivatives, which were first introduced by Cram and co-workers in 1982, are particularly fascinating due to their deep cavity and unique conformational switching between a contracted vase state and an expanded kite state [88,89]. The closed vase conformation $\left(\mathrm{C}_{4 \mathrm{v}}\right.$ symmetry) of $\mathbf{1 4}$ has a deep cavity for guest inclusion with a distance of about $0.8 \mathrm{~nm}$ between the opposite quinoxaline flaps, while the extended conformation $\left(\mathrm{C}_{2 \mathrm{v}}\right.$ symmetry) possesses a flat surface with approximately $1.25 \times 1.8 \mathrm{~nm}^{2}$ (Figure 13) [90]. Fully reversible switching from the vase to the kite conformation can be achieved upon variation of temperature [91] and $\mathrm{pH}$ [92], as well as metal ion complexation [93]. Hitherto, all the resorcinarenes incorporating BODIPY are only based on the resorcin[4]arene scaffold (vide infra), which has been extensively investigated by Diederich's group.
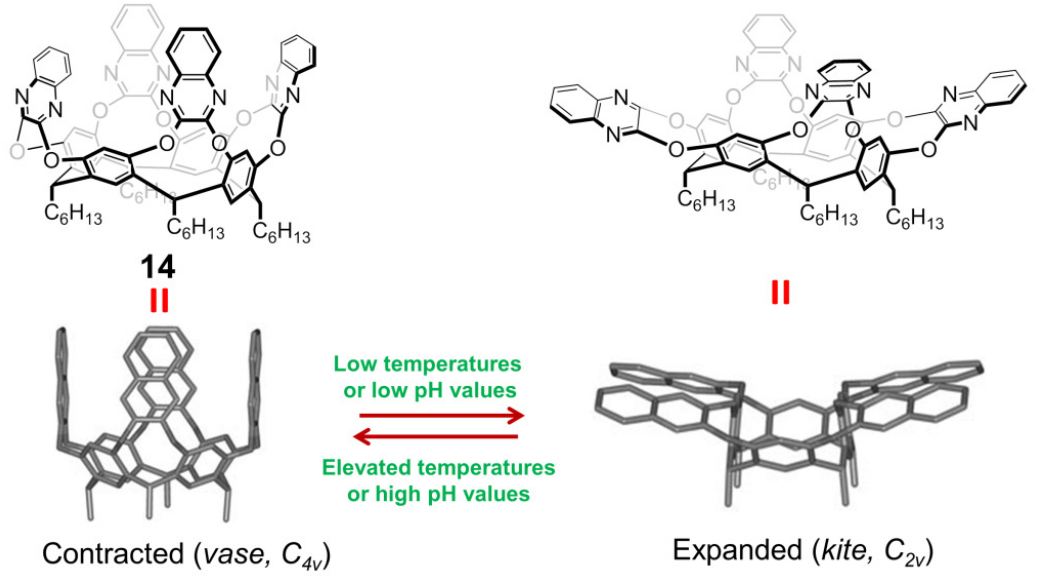

II

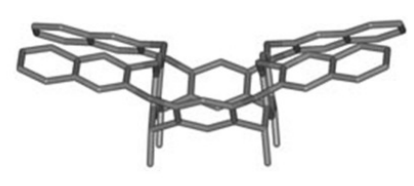

Expanded (kite, $C_{2 v}$ )

Figure 13. Unique conformational switching between a contracted vase state and an expanded kite state of quinoxaline-bridged resorcin[4]arene 14. Reproduced with permission from Reference [91]. Copyright 2006 John Wiley and Sons.

Three BODIPY-decorated resorcin[4]arenes 15-17 (Figure 14) were prepared from the corresponding double- or triply-bridged cavitands with dichloropyrazinedicarboximide BODIPY analogue through nucleophilic substitution in the presence of base. This represented the first examples of dye-labeled resorcin[4]arenes which showed a solvent-dependency of the vase-kite switching process [94]. The phenyl rings from the resorcin[4]arene backbone and BODIPY dye moieties were nearly orthogonal, featuring sharp absorption/emission bands centred at 530/540 $\mathrm{nm}$ in $\mathrm{CHCl}_{3}$, respectively. ${ }^{1} \mathrm{HNMR}$ studies of 15-17 indicated that the vase-kite switching was strongly solvent-dependent, which could be observed only in apolar, nonaromatic solvents (e.g., $\mathrm{CDCl}_{3}-\mathrm{CS}_{2}=1: 1, \mathrm{CD}_{2} \mathrm{Cl}_{2}$, and $\mathrm{C}_{2} \mathrm{D}_{2} \mathrm{Cl}_{4}$ ), meaning that solvent-cavitand interactions played a crucial role in controlling the switching process. The vase-kite transition of the three molecules could be also triggered by temperature or $\mathrm{pH}$ changes.

Subsequently, resorcin[4]arene 20 functionalized with rigid oligo(phenylene ethynylene) arms containing the donor and acceptor BODIPY dye pair was prepared by successive Sonogashira cross-coupling and deprotected reactions. The contraction-expansion switching process of $\mathbf{2 0}$ can be precisely demonstrated by fluorescence resonance energy transfer (FRET) (Figure 15) [95]. Firstly, three BODIPY-functionalized oligo(phenylene ethynylene)s 18a-c with different lengths were introduced as control compounds to verify the distance-dependent FRET properties. The FRET efficiency of 18a-c in $\mathrm{CHCl}_{3}$ decreased with increasing length of the rigid spacer, namely $98 \%$ for 18a (distance between the two BODIPY dyes, $d=1.9 \mathrm{~nm}$ ), $85 \%$ for $\mathbf{1 8 b}(d=3.2 \mathrm{~nm}$ ) and $35 \%$ for $\mathbf{1 8 c}$ $(d=5.3 \mathrm{~nm})$, which could not be affected by addition of trifluoroacetic acid (TFA). Both BODIPY-labeled cavitands 19 and 20 adopted the contracted (vase) conformation in $\mathrm{CD}_{2} \mathrm{Cl}_{2}$ or $\mathrm{CHCl}_{3}$ above $25^{\circ} \mathrm{C}$ and underwent expansion to the kite forms at $-60^{\circ} \mathrm{C}$ or upon addition of TFA. Specifically, the fluorescence emission of 19 containing the same BODIPY dyes was almost identical in its contracted and expanded 
forms, while the emission behavior of compound 20 bearing two different (donor and acceptor) BODIPY dyes differed dramatically in the two states. The UV-Vis spectrum of $\mathbf{2 0}$ in $\mathrm{CHCl}_{3}$ showed three strong absorption bands at 322, 529, and $619 \mathrm{~nm}$, which can be assigned to the oligo(phenylene ethynylene) spacers, the donor BODIPY and the acceptor dye, respectively. Meanwhile, the three absorption bands remained unchanged upon the addition of TFA. Unexpectedly, the emission of 20 in $\mathrm{CHCl}_{3}$ showed two strong peaks at $542 \mathrm{~nm}$ (donor BODIPY) and $630 \mathrm{~nm}$ (acceptor BODIPY), and the integral ratio of donor/acceptor fluorescence intensity was 45:55. The obtained relatively low FRET efficiency of 20 was quite surprising since the contracted vase conformation had been demonstrated to be most prevalent in this media. The authors ascribed the abnormal FRET behaviour to the dynamic behavior of the cavitand or unfavorable orientations of the transition dipole moments of the two dyes. Moreover, the addition of TFA resulted in the near-complete fluorescence quenching of the acceptor dye, accompanied by a double fluorescence enhancement of the donor dye, indicating that the FRET efficiency of 20 was markedly reduced due to the separation $(\approx 7 \mathrm{~nm})$ of donor and acceptor dyes in the presence of lower $\mathrm{pH}$ values. In addition, the fluorescence change could be reversed upon further neutralization with base. Later on, the synthesis of $\mathbf{1 9}$ and $\mathbf{2 0}$ as well as their analogues were thoroughly discussed [96].

Shortening the spacer length of $\mathbf{2 0}$ could afford another three BODIPY-dye-labeled resorcin[4]arene cavitands 21-23 (Figure 16a), whose conformation switching behavior was examined by both variable-temperature (VT) NMR and VT FRET experiments [97]. The vase-to-kite switching process of 20-23 could be also observed at low temperatures or after addition of a proper amount of acid. Quantitative evaluation of FRET data enabled to calculate the Förster radius $\left(R_{0}=37 \AA\right)$ for the BODIPY-dye FRET pair and the average opening angle value $\left(\alpha=16^{\circ}\right)$ in the vase conformation. In order to understand the distance distribution and dynamics between the donor/acceptor BODIPY dyes, combined experimental and molecular dynamics (MD) simulations of resorcin[4]arene cavitands 20-22 and 24-25 present in their vase and kite forms were examined in depth (Figure 16) [98]. In the kite conformation of quinone-based cavitand 25 , containing only one phenylene-ethynylene linker, the two BODIPY dyes adopted an average distance of ca. $4.2 \mathrm{~nm}$ as calculated from the MD simulations. The FRET efficiency of $\mathbf{2 5}$ in $\mathrm{CHCl}_{3}$ was determined to be $64 \%$. In terms of compounds 20-22 and 24, the longer phenylene-ethynylene linkers resulted in increasing amounts of the donor fluorescence, as indicated by the FRET efficiencies ranging from $84 \%$ (22) to $97 \%$ (20) in $\mathrm{CHCl}_{3}$. Fluorescence anisotropy measurements of the dynamics of vase $\mathbf{2 0}$ revealed that the rotation time of a BODIPY dye arm was ca. $0.15 \mathrm{~ns}$. Importantly, the fluorescence lifetime decays deduced from the MD simulations of cavitand 20 agreed very well with the experimental data. The work shown here not only presented an accurate picture of the distance distributions and dynamics in the deep-cavity of BODIPY-decorated resorcin[4]arenes, but also provided an important tool and opportunity for better understanding the behavior of other extended molecular systems.
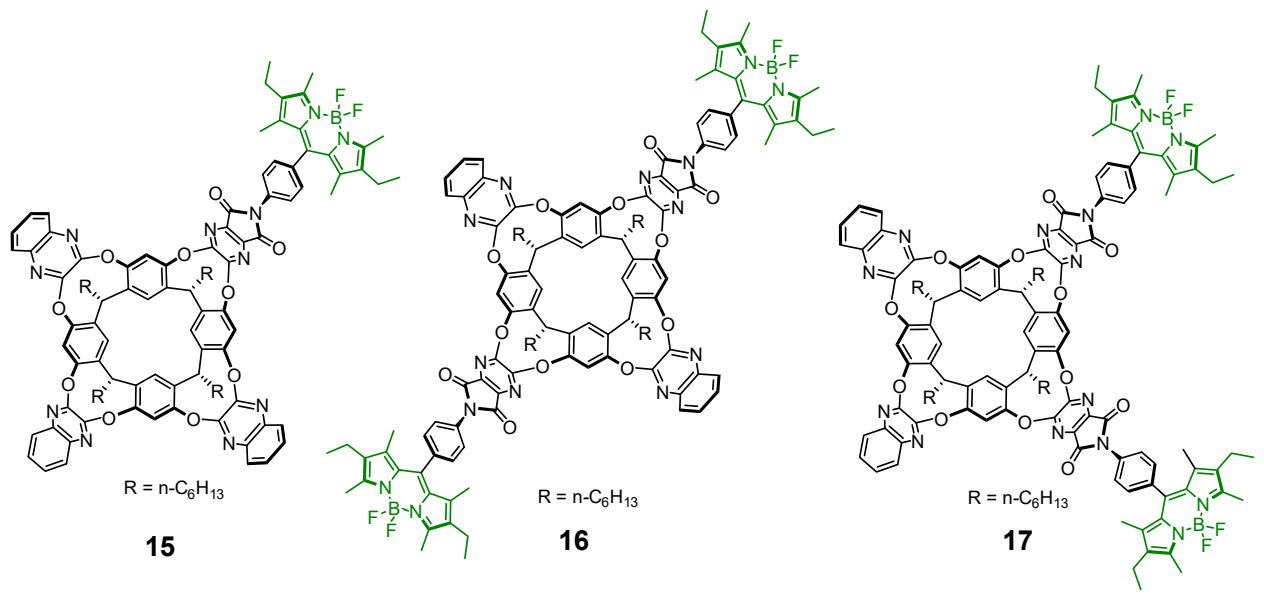

Figure 14. Chemical structures of BODIPY-decorated resorcin[4]arenes 15-17. 
(a)

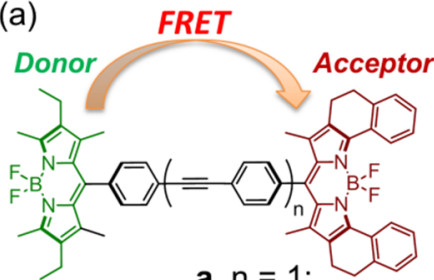

$a, n=1 ;$

$18 \mathrm{~b}, \mathrm{n}=3$

c, $n=6$

(b)

(c)
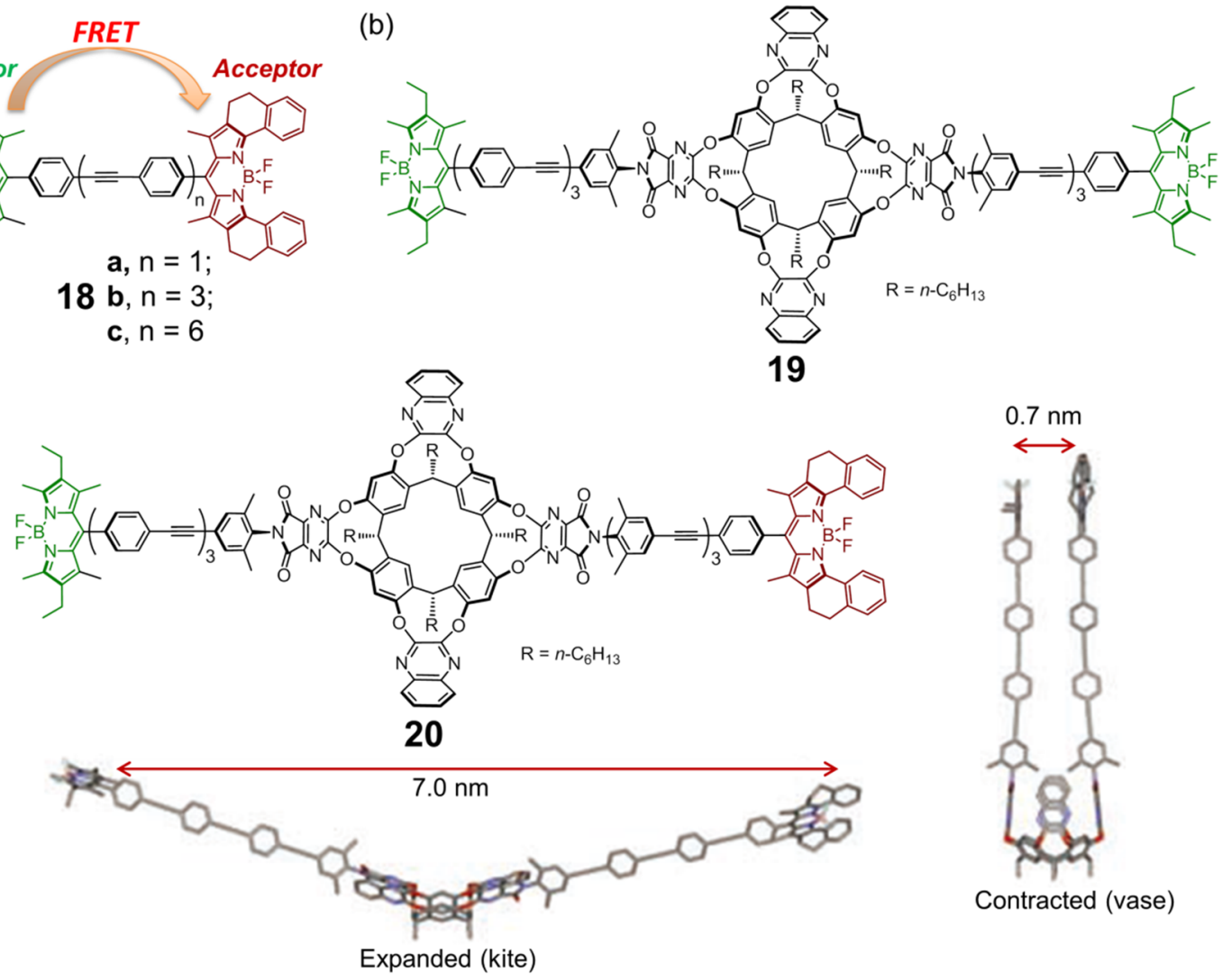

$\mathrm{R}=n-\mathrm{C}_{6} \mathrm{H}_{13}$

Figure 15. Chemical structure of (a) BODIPY-functionalized oligo(phenylene ethynylene)s 18a-c and (b) BODIPY-decorated resorcin[4]arenes 19 and (c) 20 together with its models the contracted (vase) and expanded (kite) states. Reproduced with permission from Reference [95]. Copyright 2005 John Wiley and Sons.

(a)

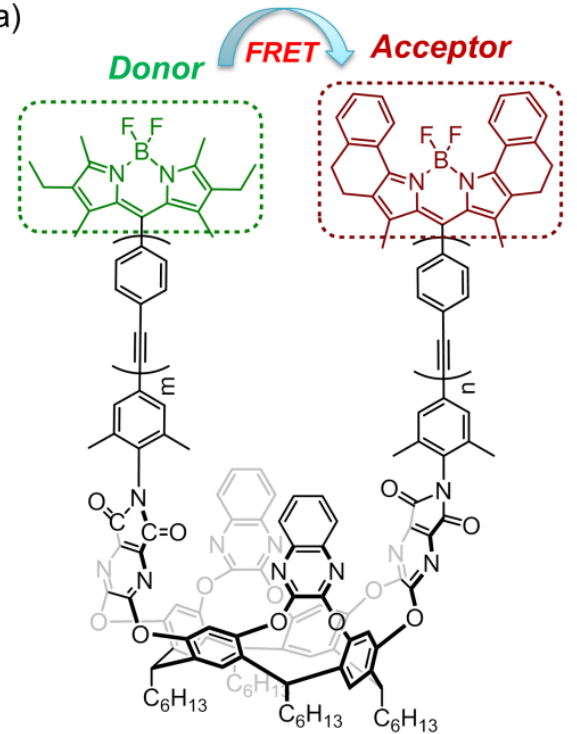

20, $\mathrm{m}=\mathrm{n}=3 ; \mathbf{2 1}, \mathrm{m}=\mathrm{n}=2$;

22, $\mathrm{m}=\mathrm{n}=1 ; \mathbf{2 3}, \mathrm{m}=\mathrm{n}=0$;

24, $m=1, n=2$ (b)

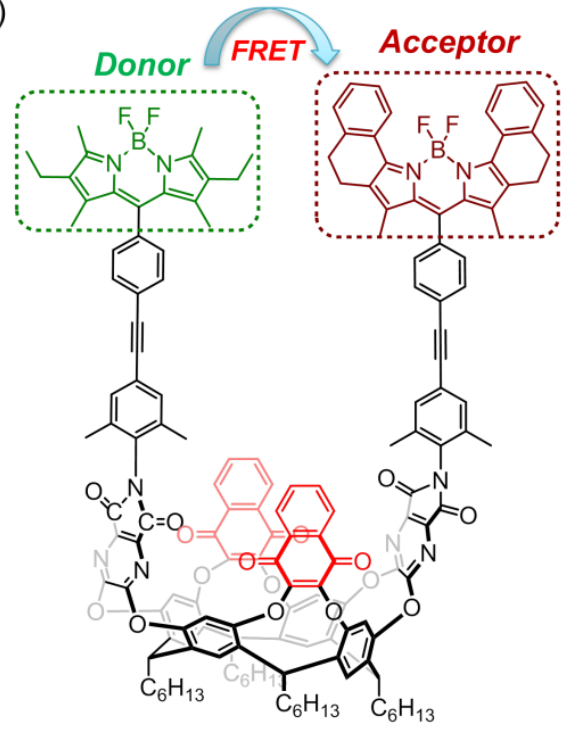

25

Figure 16. Chemical structures of BODIPY-decorated resorcin[4]arenes (a) 20-24 and (b) 25. 
In order to understand how nonradiative relaxation can affect the FRET dynamics, another BODIPY-functionalized resorcin[4]arene 26 was rationally designed and synthesized (Figure 17), whose vase and kite conformations were subjected to two-dimensional electronic spectroscopy (2DES) [99]. Being rather similar to the previous BODIPY-decorated resorcin[4]arenes, lowering the temperature or $\mathrm{pH}$ values resulted in vase-to-kite conformation transition. Specifically, temperature-induced conformation switching decreased the FRET efficiency and increased the distance of donor-acceptor BODIPY dyes from $0.5 \mathrm{~nm}$ (vase at $294 \mathrm{~K}$ ) to $3.0 \mathrm{~nm}$ (kite at $193 \mathrm{~K}$ ). Direct and independent observation of the changes in nonradiative relaxation, FRET, and residual fluorescence from the donor dye in both vase and kite conformations could be achieved via disentangling different dynamics according to the lifetimes obtained from a series of 2D spectra. Notably, the FRET rate and nonradiative relaxation extrapolated using the 2DES method differed significantly from the results determined from standard lifetime-based measurements. The findings of the work shown here not only presented the fact that the competing nonradiative relaxation processes must be taken into account in order to obtain accurate FRET efficiencies, but more importantly, these will enable improved FRET efficiency measurements in other complicated biological systems and advanced materials.

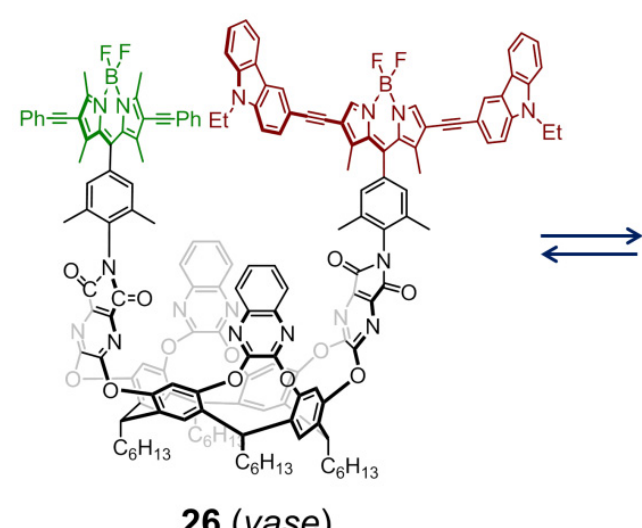

26 (vase)

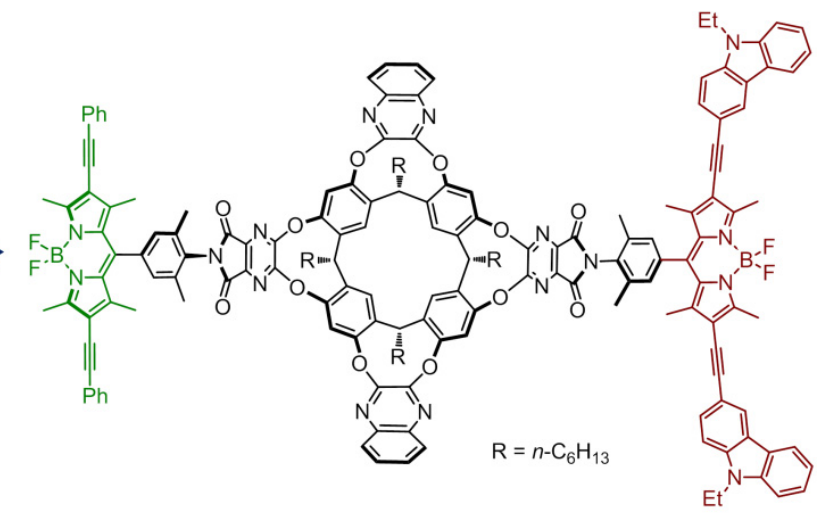

26 (kite)

Figure 17. Chemical structure of BODIPY-decorated resorcin[4]arenes 26 and its vase-to-kite conformation transition.

\section{Pillararenes Substituted with BODIPY}

\subsection{Chemosensors}

Up until now, only one example has been associated with a chemosensor constructed from pillararene substituted with BODIPY. Recently, Kursunlu and coworkers designed and synthesized pillar[5]arene derivative 27 functionalized with ten BODIPY groups on both rims using the classic Copper-Catalyzed azide/alkyne cycloaddition (CuAAC) click reaction (Figure 18), which could act as a turn-on fluorescence chemosensor for selective recognition of L-Asn [100]. When 20 equivalents of thirteen different amino acids were added to the DMF- $\mathrm{H}_{2} \mathrm{O}(1: 1, v / v)$ media, only in the presence of L-Asn the very weak fluorescence emission of 27 centered at $520 \mathrm{~nm}$ was dramatically enhanced together with a slightly blue-shift $(6 \mathrm{~nm})$ and a new fluorescence band that appeared at $425 \mathrm{~nm}$. Meanwhile, the addition of L-Asn also led to an obvious enhancement of the absorption bands at 325 and $505 \mathrm{~nm}$. These spectral changes combined with the naked-eye observable fluorescence color transition could be attributed to the formation of a unique host-guest complex with 1:1 stoichiometry. The binding constant and dection limit of 27 for L-Asn was determined to be $2.45 \times 10^{8} \mathrm{M}^{-1}$ and $3.51 \times 10^{-7} \mathrm{M}$, respectively. 


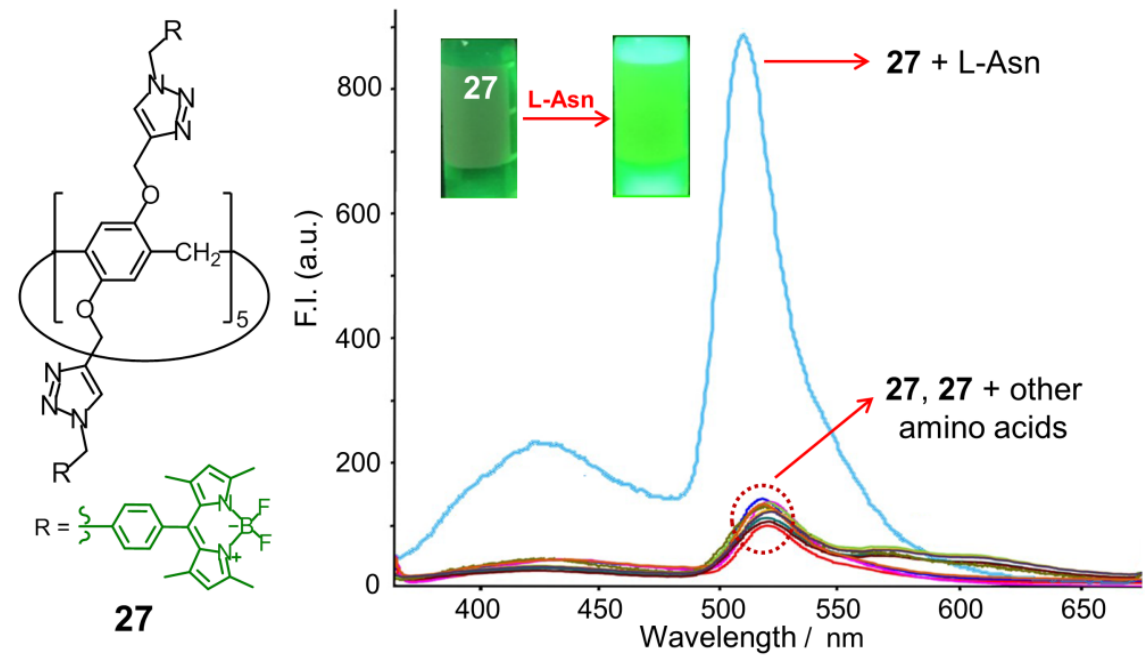

Figure 18. BODIPY-functionalized pillar[5]arene 27 for selective turn-on fluorescence recognition of L-Asn in DMF- $\mathrm{H}_{2} \mathrm{O}(1: 1, v / v)$ media. Reproduced with permission from Reference [100]. Copyright 2020 Elsevier.

\subsection{Supramolecular Assembly Systems}

Benefitting from the distinct advantages of noncovalent interactions and/or dynamic covalent connections, supramolecular assembly not only leads to unique physical and chemical properties, but also shows inherent adaptability and reversibility with sophisticated functions, which represents an efficient and facile methodology to construct discrete and high-ordered structures with responsiveness to multiple stimuli [101]. Supramolecular polymers are among the typical examples, which have been receiving increasing attention currently [102]. In 2015, Wang and coworkers constructed linear and cross-linked supramolecular polymers in $\mathrm{CHCl}_{3}$ based on a BODIPY-bridged pillar[5]arene dimer 28 with two BODIPY derivatives guests G1 and G2, respectively (Figure 19) [103]. The supramolecular polymerization process was confirmed by ${ }^{1} \mathrm{H}$ NMR, 2D NOESY, 2D diffusion-ordered NMR spectroscopy (DOSY), and SEM experiments, owing to the strong host-guest interaction between the pillar[5]arene cavity and the alkyl chains from the neutral guests through multiple $\mathrm{C}-\mathrm{H} \ldots \pi$ interactions and $\mathrm{C}-\mathrm{H} \ldots \mathrm{N} / \mathrm{C}-\mathrm{H} \ldots \mathrm{O}$ hydrogen bonds. In good accordance with their chemical structures, the 28-G1 and 28-G2 assembly has a stoichiometry of 1:1 and 3:2 (28:G2), respectively. The UV-vis absorption of the two assemblies showed strong absorptions in a wide region from 300 to $700 \mathrm{~nm}$, which were equal to the superposed patterns of individual components $\mathbf{2 8}$ and $\mathbf{G 1}$ or G2. Intriguingly, the fluorescence band of $\mathbf{2 8}$ centered at $522 \mathrm{~nm}$ was gradually reduced upon addition of either of the guests, together with the appearance of a new fluorescence band at $595 \mathrm{~nm}$ for $\mathbf{G 1}$ or $669 \mathrm{~nm}$ for G2, demonstrating that efficient FRET effects were obtained for both assemblies. Meanwhile, these fluorescence responses were accompanied by naked-eye observable fluorescent color changes from green to yellow (G1) or pink (G2).

Subsequently, Wang's group reported $\mathrm{pH}$-responsive supramolecular vesicles constructed from water-soluble pillar[5]arene 29 and a BODIPY derivative G3 for chemo-photodynamic dual therapy (Figure 20) [104]. In detail, BODIPY derivative G3, acting as both the guest and photosensitizer, could insert into the cavity of pillar[5]arene 29 to form an amphiphile 29-G3 host-guest complex with 1:1 stoichiometry, which further self-assembled into supramolecular vesicles with good biocompatibility driven by the amphiphilic properties of the complex and $\pi-\pi$ stacking interactions of BODIPY backbone. In addition, the chemotherapy drug doxorubicin (DOX) could be encapsulated (encapsulation efficiency: $14 \%$ ) into the vesicle assembly. The resulting formed DOX-loaded vesicles were stable under physiological conditions, whereas they showed effective and rapid DOX release in low-pH environment due to the protonation of $\mathbf{2 9}$ and disassembly of the vesicles. Importantly, such DOX-loaded vesicles could localize well in lysosomes and exhibited an obvious combination of chemo- and photodynamic 
activities against A549 cancer cells, which is the first example of combination of chemotherapy and photodynamic therapy in pillararene-based supramolecular assembly.

Rotaxanes and catenanes are two archetypal examples of mechanically interlocked molecules [105]. Xiao and coworkers constructed the first BODIPY-derived fluorescent [2]rotaxane (Figure 21), which showed unique molecular shuttle properties under multiple external stimuli including solvent polarity and temperature [106]. Here, 1,4-diethoxypillar[5]arene 30 acted as the wheel, while guest G4 was introduced as the axle where a BODIPY chromophore and arylcarbamic group were introduced as the stoppers. Decreasing the solvent polarity or increasing the temperature resulted in a moving of the pillar[5]arene moiety from the methylene groups adjacent to the carbamic stopper to the imidazolium unit, which was accompanied by a fluorescence quenching response (quenching efficiency: $23 \%$ from $\mathrm{CHCl}_{3}$ to dimethylsulfoxide (DMSO), and $52 \%$ at $115^{\circ} \mathrm{C}$ in comparison to $25^{\circ} \mathrm{C}$ ). Meanwhile, the fluorescence intensity of the [2]rotaxane could be turned off and on repeatedly with the alternate addition of triethylamine and trifluoroacetic acid. Intriguingly, the fluorescent [2]rotaxane could further self-assemble in DMSO media into a supramolecular gel, which exhibited reversible gel-sol phase transitions upon heating/cooling, shaking/resting, acid/base, or addition of different anions. Importantly, the obtained supramolecular gel could be exploited as a fluorescent film sensor for the detection of $\mathrm{HCl}$ or ammonia vapor, implying practical application of the gel in gas detecting.
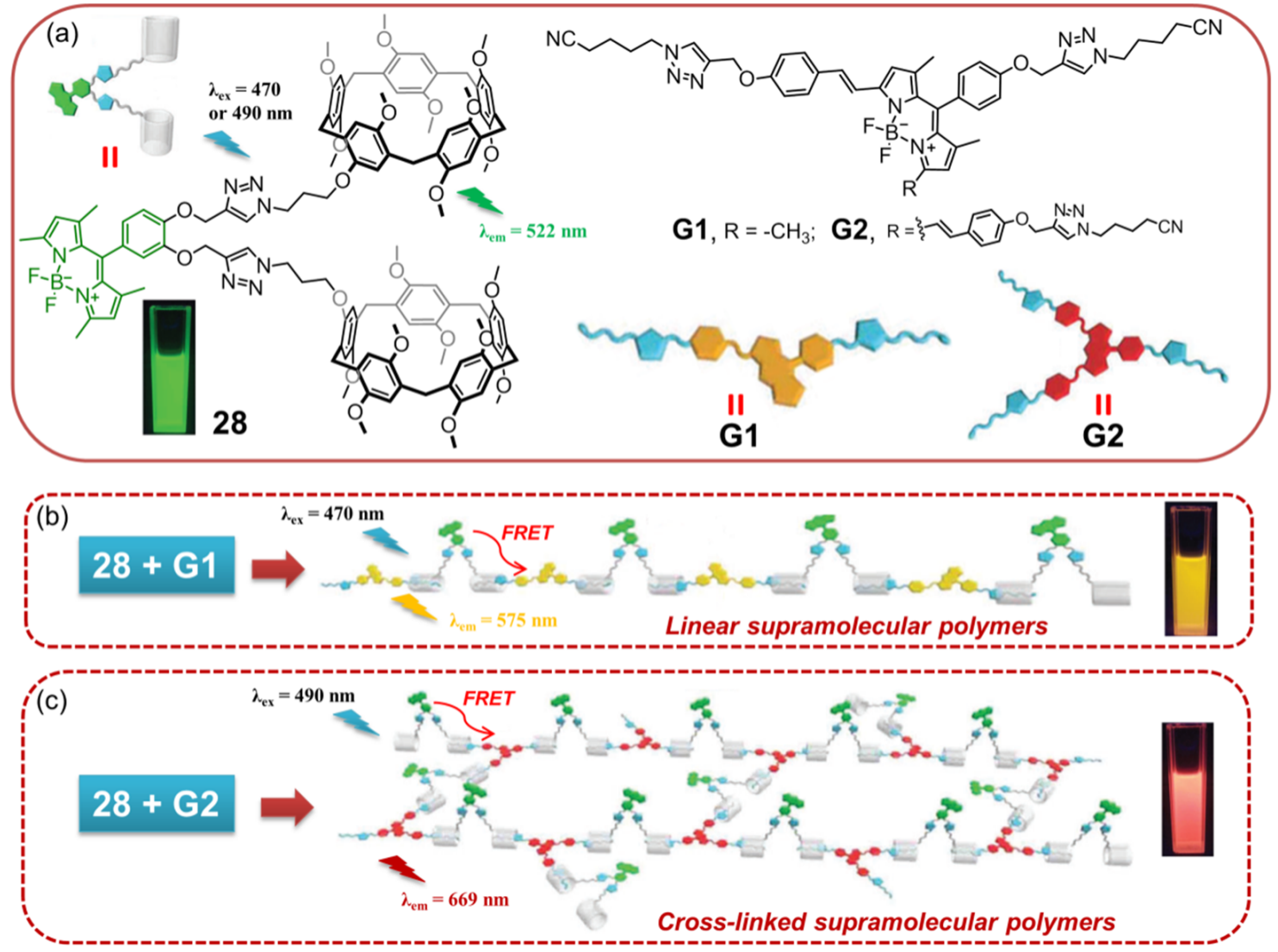

Figure 19. (a) Chemical structures of BODIPY-bridged pillar[5]arene dimer 28 and two BODIPY derivative guests G1 and G2; construction of fluorescence resonance energy transfer (FRET)-capable (b) linear and (c) cross-linked supramolecular polymers based on 28 with G1 and G2, respectively. Reproduced with permission from Reference [103]. Copyright 2015 Royal Society of Chemistry. 


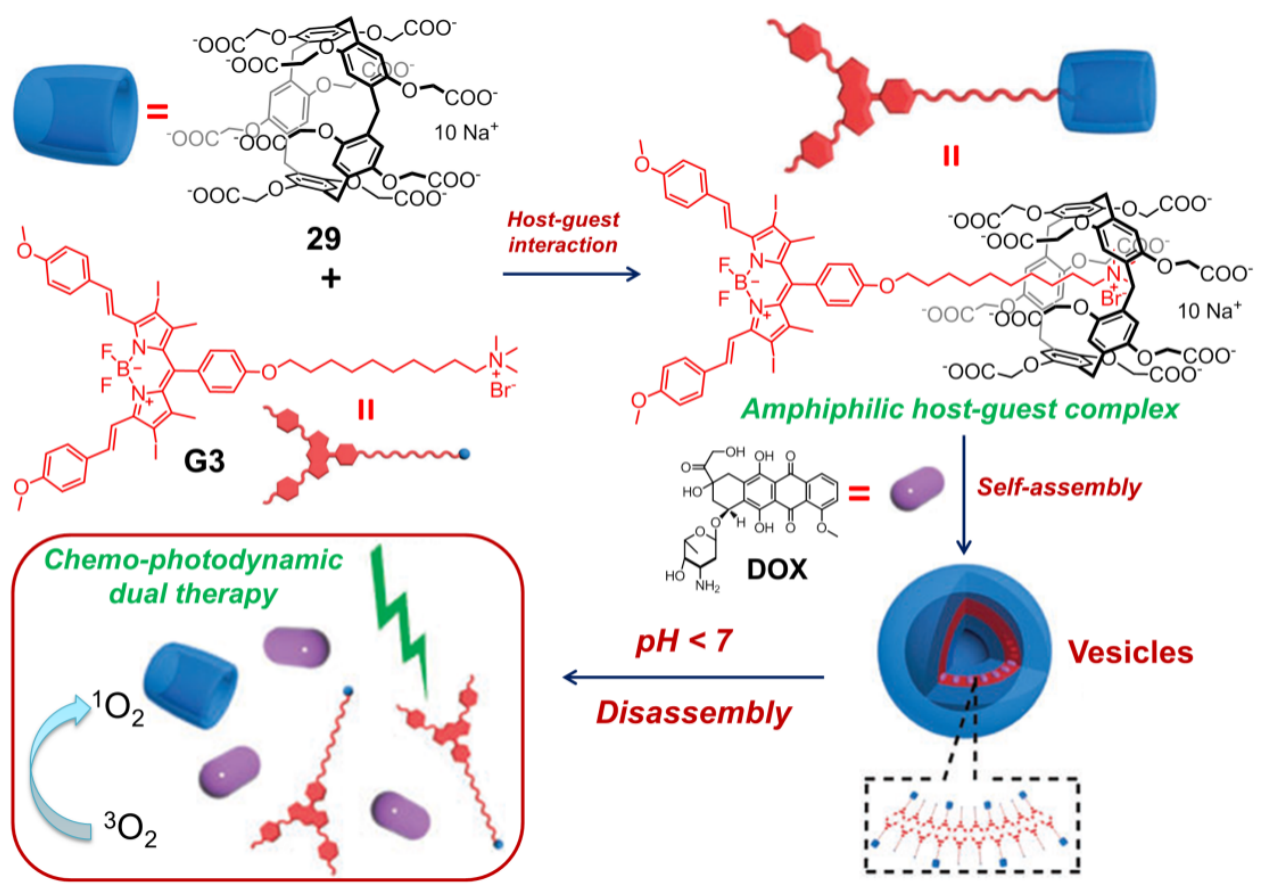

Figure 20. $\mathrm{pH}$-sesponsive supramolecular vesicles assembled by water-soluble pillar[5]arene 29 and a BODIPY derivative G3 for chemo-photodynamic dual therapy. Reproduced with permission from Reference [104]. Copyright 2015 Royal Society of Chemistry.

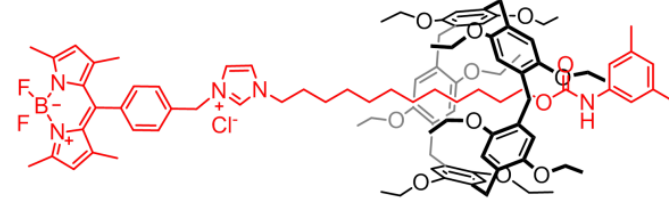

In DMSO, lower temperature

In $\mathrm{CHCl}_{3}$, higher temperature

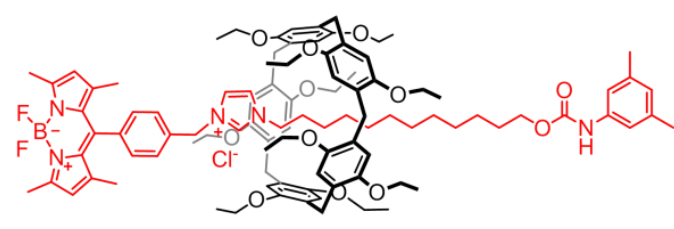

30-G4

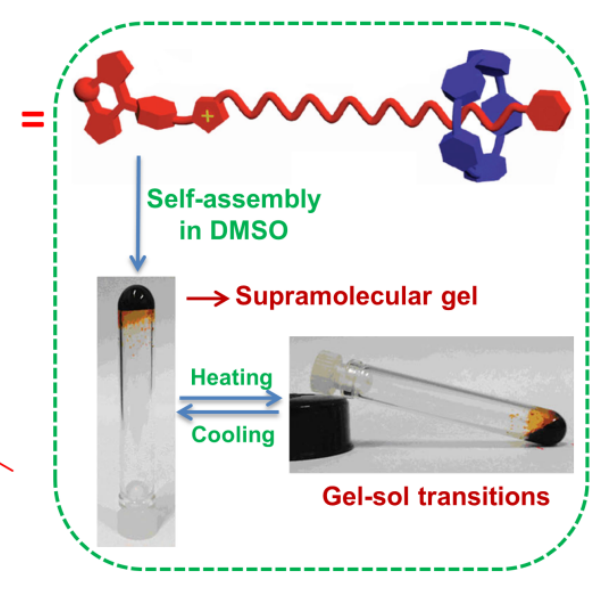

Figure 21. Multistimuli sensitive behavior of BODIPY-involved fluorescent [2] rotaxane 30-G4 and its corresponding self-assembly of supramolecular gel in dimethylsulfoxide (DMSO).

\subsection{Mimicking Light Harvesting System}

Mimicking light-harvesting systems using artificial models has attracted intensive interest not only due to their promising applications in various fields but also owing to the fact that this is an effective strategy to better understand the function and mechanism of photosynthesis [107-109]. Actually, the first example of pillararene-based mimicking the light-harvesting system was achieved by the assemblies of 28-G1 and 28-G2. Nevertheless, these two artificial light-harvesting systems only showed moderate fluorescence resonance energy transfer efficiencies (51\% for $\mathbf{2 8 - G 1}$ and $63 \%$ for 28-G2 in $\mathrm{CHCl}_{3}$ ) because of the inherently non-covalent binding manners. In 2018, another artificial light-harvesting system constructed by BODIPY-incorporated pillar[5]arene 31 was developed with an effective FRET (Figure 22), however, in a covalent donor-acceptor model [110]. Specifically, BODIPY 
perfunctionalized pillar[5]arene 31 worked very well for mimicking a light harvesting system with a higher energy transfer efficiency up to $92 \%$.
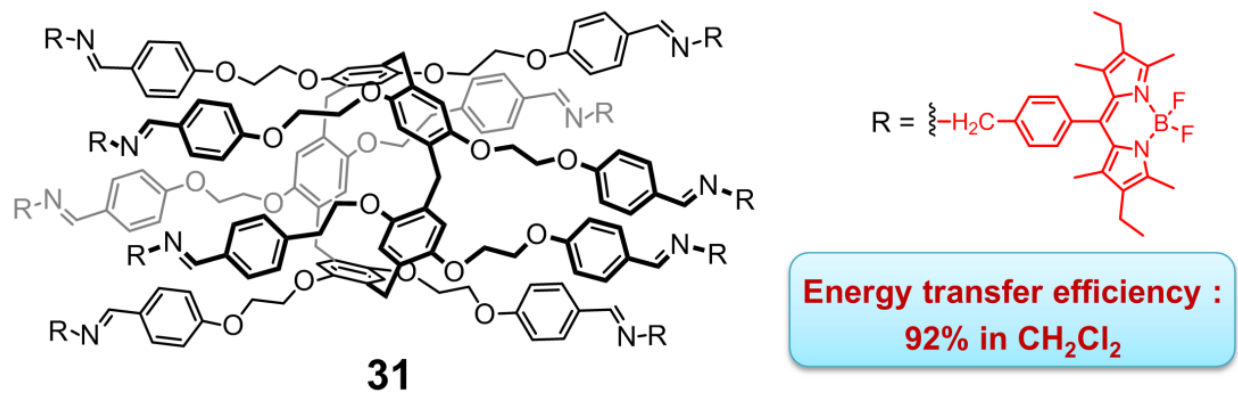

Figure 22. Chemical structure of BODIPY perfunctionalized pillar[5]arene 31 for mimicking the light harvesting system.

\section{Summary and Outlook}

To conclude, we discussed the progress made so far of macrocyclic arenes substituted with BODIPY for multiple applications ranging from chemosensors to construction of smart materials, which represents the first comprehensive summary in both macrocycles and BODIPY chemistry. Only the calixarenes, resorcinarenes, and pillararenes were presented as no other macrocyclic arenes functionalized with BODIPY units were reported at the present time. It is interesting to note that each of the three types of macrocyclic arenes substituted with BODIPY were derived from the smallest possible scaffold, i.e., calix[4]arene, resorcin[4]arene, and pillar[5]arene. BODIPY-functionalized calix[4]arenes have been successfully applied to construct fluorescent chemosensors for metal ions, $\mathrm{pH}$ sensing, photosensitizers, and electronic energy transfer devices. Well-defined resorcin[4]arenes decorated with specific BODIPY moieties provide an important tool for better understanding the behavior of conformational switching and photophysical processes. Pillar[5]arenes functionalized with BODIPY groups were proven to be efficient building blocks in the construction of versatile host-guest recognition systems and supramolecular assemblies.

Despite great achievement in the research area of macrocyclic arenes incorporating BODIPY, there are still extensive challenges and aspects that need to be considered in the future. To name but a few, for the macrocyclic arenes, no examples of calix[n]arenes (n $>4)$ and pillar[n]arenes $(n>5)$ with larger sizes have been combined with BODIPY, and their selective recognition properties might be quite intriguing. Meanwhile, water soluble or amphiphilic macrocyclic arenes will be prone to construct distinct host-guest systems and to cause supramolecular assembly. In terms of BODIPY dyes, more efforts should be paid to near infrared (NIR) emissive fluorophores in association with multiple fluorescence mechanisms. As the potential application is concerned, it is tempting to apply macrocyclic arenes functionalized with BODIPY in more interdisciplinary research areas (e.g., photophysics, biomedicine, stimuli-responsive materials, etc.). Needless to say, the research of macrocyclic arenes substituted with BODIPY units is a rising star in supramolecular chemistry and still has an infinite number of possibilities. We hope this review will facilitate and inspire more efforts in this field, and new discoveries can be expected in the near future.

Funding: This research received no external funding.

Acknowledgments: Jianjun Huang thanks the fellowship from China Scholarship Council (CSC) for providing a doctoral scholarship. Yuyu Fang appreciates the fellowship from CSC (No. 201908510001) for Visiting Scholar Program. Wim Dehaen acknowledges project financing from KU Leuven, grant number C14/19/78.

Conflicts of Interest: The authors declare no conflict of interest. 


\section{List of Abbreviations}

$\begin{array}{ll}\text { BODIPY } & \text { Boron-dipyrromethene, 4,4-difluoro-4-bora-3a, 4a-diaza-s-indacenes } \\ \text { CT } & \text { Charge transfer } \\ \text { CuAAC } & \text { Copper-Catalyzed azide/alkyne cycloaddition } \\ \text { 2DES } & \text { Two-dimensional electronic spectroscopy } \\ \text { DDQ } & \text { 2,3-Dichloro-5,6-dicyano-1,4-benzoquinone } \\ \text { DFT } & \text { Density functional theory } \\ \text { DMF } & \text { N,N-dimethylformamide } \\ \text { DMSO } & \text { Dimethylsulfoxide } \\ \text { DOX } & \text { Doxorubicin } \\ \text { EET } & \text { Electronic energy transfer } \\ \text { ESIPT } & \text { Excited-state intermolecular proton transfer } \\ \text { FRET } & \text { Fluorescence resonance energy transfer } \\ { }^{1} \text { H NMR } & \text { Proton nuclear magnetic resonance } \\ \text { ICT } & \text { Intramolecular charge transfer } \\ \text { IUPAC } & \text { International Union of Pure and Applied Chemistry } \\ \text { MD } & \text { Molecular dynamics } \\ \text { MLCT } & \text { Metal-to-ligand charge transfer } \\ \text { NIR } & \text { Near infrared } \\ \text { PDT } & \text { Photodynamic therapy } \\ \text { PEG } & \text { Polyethylene glycol } \\ \text { PET } & \text { Photo-induced electron transfer } \\ \text { PVC } & \text { Polyvinyl chloride } \\ \text { ROS } & \text { Reactive oxygen species } \\ \text { SEM } & \text { Scanning electron microscope } \\ \text { TDMACl } & \text { Tridodecylmethylammonium chloride } \\ \text { TD-DFT } & \text { Time dependent-density functional theory } \\ \text { TFA } & \text { Trifluoroacetic acid } \\ \text { VT FRET } & \text { Variable-temperature fluorescence resonance energy transfer } \\ \text { VT NMR } & \text { Variable-temperature nuclear magnetic resonance } \\ & \end{array}$

\section{References}

1. Atwood, J.L. Comprehensive Supramolecular Chemistry II.; Elsevier: Amsterdam, The Netherlands, 2017.

2. Diederich, F.; Stang, P.J.; Tykwinski, R.R. Modern Supramolecular Chemistry: Strategies for Macrocycle Synthesis; John Wiley \& Sons: New York, NY, USA, 2008.

3. Li, J.; Yim, D.; Jang, W.-D.; Yoon, J. Recent progress in the design and applications of fluorescence probes containing crown ethers. Chem. Soc. Rev. 2017, 46, 2437-2458. [CrossRef] [PubMed]

4. Crini, G. Review: A history of cyclodextrins. Chem. Rev. 2014, 114, 10940-10975. [CrossRef] [PubMed]

5. Kumar, R.; Sharma, A.; Singh, H.; Suating, P.; Kim, H.S.; Sunwoo, K.; Shim, I.; Gibb, B.C.; Kim, J.S. Revisiting Fluorescent Calixarenes: From Molecular Sensors to Smart Materials. Chem. Rev. 2019, 119, 9657-9721. [CrossRef]

6. Biros, S.M.; Rebek, J., Jr. Structure and binding properties of water-soluble cavitands and capsules. Chem. Soc. Rev. 2007, 36, 93-104. [CrossRef] [PubMed]

7. Lü, J.; Lin, J.-X.; Cao, M.-N.; Cao, R. Cucurbituril: A promising organic building block for the design of coordination compounds and beyond. Coordin. Chem. Rev. 2013, 257, 1334-1356. [CrossRef]

8. Chen, C.F.; Han, Y. Triptycene-Derived Macrocyclic Arenes: From Calixarenes to Helicarenes. Acc. Chem. Res. 2018, 51, 2093-2106. [CrossRef] [PubMed]

9. Lindoy, L.F.; Park, K.M.; Lee, S.S. Metals, macrocycles and molecular assemblies-macrocyclic complexes in metallo-supramolecular chemistry. Chem. Soc. Rev. 2013, 42, 1713-1727. [CrossRef] [PubMed]

10. Gong, B.; Shao, Z. Self-Assembling Organic Nanotubes with Precisely Defined, Sub-nanometer Pores: Formation and Mass Transport Characteristics. Acc. Chem. Res. 2013, 46, 2856-2866. [CrossRef]

11. Han, X.N.; Han, Y.; Chen, C.F. Pagoda[4]arene and i-Pagoda[4]arene. J. Am. Chem. Soc. 2020, 142, 8262-8269. [CrossRef] 
12. Della Sala, P.; Del Regno, R.; Talotta, C.; Capobianco, A.; Hickey, N.; Geremia, S.; De Rosa, M.; Spinella, A.; Soriente, A.; Neri, P.; et al. Prismarenes: A New Class of Macrocyclic Hosts Obtained by Templation in a Thermodynamically Controlled Synthesis. J. Am. Chem. Soc. 2020, 142, 1752-1756. [CrossRef] [PubMed]

13. Xu, K.; Zhang, Z.Y.; Yu, C.; Wang, B.; Dong, M.; Zeng, X.; Gou, R.; Cui, L.; Li, C. A Modular Synthetic Strategy for Functional Macrocycles. Angew. Chem. Int. Ed. 2020, 59, 7214-7218. [CrossRef] [PubMed]

14. Yang, W.; Samanta, K.; Wan, X.; Thikekar, T.U.; Chao, Y.; Li, S.; Du, K.; Xu, J.; Gao, Y.; Zuilhof, H.; et al. Tiara[5]arenes: Synthesis, Solid-State Conformational Studies, Host-Guest Properties, and Application as Nonporous Adaptive Crystals. Angew. Chem. Int. Ed. 2020, 59, 3994-3999. [CrossRef] [PubMed]

15. Yang, L.P.; Jiang, W. Prismarene: An Emerging Naphthol-Based Macrocyclic Arene. Angew. Chem. Int. Ed. 2020, 59. [CrossRef] [PubMed]

16. Wang, Y.; Xu, K.; Li, B.; Cui, L.; Li, J.; Jia, X.; Zhao, H.; Fang, J.; Li, C. Efficient Separation of cis- and trans-1,2-Dichloroethene Isomers by Adaptive Biphen[3]arene Crystals. Angew. Chem. Int. Ed. 2019, 58, 10281-10284. [CrossRef] [PubMed]

17. Li, B.; Wang, B.; Huang, X.; Dai, L.; Cui, L.; Li, J.; Jia, X.; Li, C. Terphen[n]arenes and Quaterphen[n]arenes ( $\mathrm{n}=3-6)$ : One-Pot Synthesis, Self-Assembly into Supramolecular Gels, and Iodine Capture. Angew. Chem. Int. Ed. 2019, 58, 3885-3889. [CrossRef] [PubMed]

18. Pan, Y.-C.; Hu, X.-Y.; Guo, D.-S. Biomedical Applications of Calixarenes: State-of-the-Art and Perspectives. Angew. Chem. Int. Ed. 2020. [CrossRef] [PubMed]

19. Kim, H.J.; Lee, M.H.; Mutihac, L.; Vicens, J.; Kim, J.S. Host-guest sensing by calixarenes on the surfaces. Chem. Soc. Rev. 2012, 41, 1173-1190. [CrossRef] [PubMed]

20. Nimse, S.B.; Kim, T. Biological applications of functionalized calixarenes. Chem. Soc. Rev. 2013, 42, 366-386. [CrossRef]

21. Tian, H.-W.; Liu, Y.-C.; Guo, D.-S. Assembling features of calixarene-based amphiphiles and supra-amphiphiles. Mater. Chem. Front. 2020, 4, 46-98. [CrossRef]

22. Timmerman, P.; Verboom, W.; Reinhoudt, D.N. Resorcinarenes. Tetrahedron 1996, 52, 2663-2704. [CrossRef]

23. Gramage-Doria, R.; Armspach, D.; Matt, D. Metallated cavitands (calixarenes, resorcinarenes, cyclodextrins) with internal coordination sites. Coordin. Chem. Rev. 2013, 257, 776-816. [CrossRef]

24. Pochorovski, I.; Diederich, F. Fluorophore-Functionalized and Top-Covered Resorcin[4]arene Cavitands. Isr. J. Chem. 2012, 52, 20-29. [CrossRef]

25. Yu, Y.; Yang, J.-M.; Rebek, J. Molecules in Confined Spaces: Reactivities and Possibilities in Cavitands. Chem 2020. [CrossRef]

26. Pinalli, R.; Pedrini, A.; Dalcanale, E. Environmental Gas Sensing with Cavitands. Chem. Eur. J. 2018, 24, 1010-1019. [CrossRef] [PubMed]

27. Kobayashi, K.; Yamanaka, M. Self-assembled capsules based on tetrafunctionalized calix[4]resorcinarene cavitands. Chem. Soc. Rev. 2015, 44, 449-466. [CrossRef] [PubMed]

28. Pochorovski, I.; Diederich, F. Development of redox-switchable resorcin[4]arene cavitands. Acc. Chem. Res. 2014, 47, 2096-2105. [CrossRef] [PubMed]

29. Natarajan, N.; Brenner, E.; Sémeril, D.; Matt, D.; Harrowfield, J. The Use of Resorcinarene Cavitands in Metal-Based Catalysis. Eur. J. Org. Chem. 2017, 6100-6113. [CrossRef]

30. Murray, J.; Kim, K.; Ogoshi, T.; Yao, W.; Gibb, B.C. The aqueous supramolecular chemistry of cucurbit[n]urils, pillar[n]arenes and deep-cavity cavitands. Chem. Soc. Rev. 2017, 46, 2479-2496. [CrossRef]

31. Ogoshi, T.; Kanai, S.; Fujinami, S.; Yamagishi, T.-a.; Nakamoto, Y. para-Bridged Symmetrical Pillar[5]arenes: Their Lewis Acid Catalyzed Synthesis and Host-Guest Property. J. Am. Chem. Soc. 2008, 130, 5022-5023. [CrossRef]

32. Xue, M.; Yang, Y.; Chi, X.; Zhang, Z.; Huang, F. Pillararenes, a new class of macrocycles for supramolecular chemistry. Acc. Chem. Res. 2012, 45, 1294-1308. [CrossRef]

33. Ogoshi, T.; Yamagishi, T.A.; Nakamoto, Y. Pillar-Shaped Macrocyclic Hosts Pillar[n]arenes: New Key Players for Supramolecular Chemistry. Chem. Rev. 2016, 116, 7937-8002. [CrossRef] [PubMed]

34. Si, W.; Xin, P.; Li, Z.T.; Hou, J.L. Tubular Unimolecular Transmembrane Channels: Construction Strategy and Transport Activities. Acc. Chem. Res. 2015, 48, 1612-1619. [CrossRef] [PubMed]

35. Jie, K.; Zhou, Y.; Li, E.; Huang, F. Nonporous Adaptive Crystals of Pillararenes. Acc. Chem. Res. 2018, 51, 2064-2072. [CrossRef] [PubMed] 
36. Zhang, H.; Liu, Z.; Zhao, Y. Pillararene-based self-assembled amphiphiles. Chem. Soc. Rev. 2018, 47, 5491-5528. [CrossRef] [PubMed]

37. Feng, W.; Jin, M.; Yang, K.; Pei, Y.; Pei, Z. Supramolecular delivery systems based on pillararenes. Chem. Commun. 2018, 54, 13626-13640. [CrossRef]

38. Song, N.; Lou, X.Y.; Ma, L.; Gao, H.; Yang, Y.W. Supramolecular nanotheranostics based on pillarenes. Theranostics 2019, 9, 3075-3093. [CrossRef] [PubMed]

39. Fa, S.; Kakuta, T.; Yamagishi, T.-a.; Ogoshi, T. One-, Two-, and Three-Dimensional Supramolecular Assemblies Based on Tubular and Regular Polygonal Structures of Pillar[n]arenes. CCS Chem. 2019, 1, 50-63. [CrossRef]

40. Li, H.; Yang, Y.; Xu, F.; Liang, T.; Wen, H.; Tian, W. Pillararene-based supramolecular polymers. Chem. Commun. 2019, 55, 271-285. [CrossRef]

41. Chen, L.; Cai, Y.; Feng, W.; Yuan, L. Pillararenes as macrocyclic hosts: A rising star in metal ion separation. Chem. Commun. 2019, 55, 7883-7898. [CrossRef]

42. Fang, Y.; Deng, Y.; Dehaen, W. Tailoring pillararene-based receptors for specific metal ion binding: From recognition to supramolecular assembly. Coordin. Chem. Rev. 2020, 415, 213313. [CrossRef]

43. Banuelos, J. BODIPY Dye, the Most Versatile Fluorophore Ever? Chem. Rec. 2016, 16, 335-348. [CrossRef] [PubMed]

44. Treibs, A.; Kreuzer, F.-H. Difluorboryl-Komplexe von Di- und Tripyrrylmethenen. Justus Liebigs Ann. Chem. 1968, 718, 208-223. [CrossRef]

45. Shah, M.; Thangaraj, K.; Soong, M.L.; Wolford, L.T.; Boyer, J.H.; Politzer, I.R.; Pavlopoulos, T.G. Pyrromethene-BF2 complexes as laser dyes: 1. Heteroat. Chem. 1990, 1, 389-399. [CrossRef]

46. Boens, N.; Leen, V.; Dehaen, W. Fluorescent indicators based on BODIPY. Chem. Soc. Rev. 2012, 41, 1130-1172. [CrossRef] [PubMed]

47. Boens, N.; Verbelen, B.; Dehaen, W. Postfunctionalization of the BODIPY Core: Synthesis and Spectroscopy. Eur. J. Org. Chem. 2015, 6577-6595. [CrossRef]

48. Boodts, S.; Fron, E.; Hofkens, J.; Dehaen, W. The BOPHY fluorophore with double boron chelation: Synthesis and spectroscopy. Coordin. Chem. Rev. 2018, 371, 1-10. [CrossRef]

49. Boens, N.; Verbelen, B.; Ortiz, M.J.; Jiao, L.; Dehaen, W. Synthesis of BODIPY dyes through postfunctionalization of the boron dipyrromethene core. Coordin. Chem. Rev. 2019, 399, 213024. [CrossRef]

50. Ni, Y.; Wu, J. Far-red and near infrared BODIPY dyes: Synthesis and applications for fluorescent $\mathrm{pH}$ probes and bio-imaging. Org. Biomol. Chem. 2014, 12, 3774-3791. [CrossRef]

51. Zhang, J.; Wang, N.; Ji, X.; Tao, Y.; Wang, J.; Zhao, W. BODIPY-Based Fluorescent Probes for Biothiols. Chem. Eur. J. 2020, 26, 4172-4192. [CrossRef]

52. Kolemen, S.; Akkaya, E.U. Reaction-based BODIPY probes for selective bio-imaging. Coordin. Chem. Rev. 2018, 354, 121-134. [CrossRef]

53. Kowada, T.; Maeda, H.; Kikuchi, K. BODIPY-based probes for the fluorescence imaging of biomolecules in living cells. Chem. Soc. Rev. 2015, 44, 4953-4972. [CrossRef] [PubMed]

54. Nepomnyashchii, A.B.; Bard, A.J. Electrochemistry and electrogenerated chemiluminescence of BODIPY dyes. Acc. Chem. Res. 2012, 45, 1844-1853. [CrossRef] [PubMed]

55. Bessette, A.; Hanan, G.S. Design, synthesis and photophysical studies of dipyrromethene-based materials: Insights into their applications in organic photovoltaic devices. Chem. Soc. Rev. 2014, 43, 3342-3405. [CrossRef] [PubMed]

56. Kamkaew, A.; Lim, S.H.; Lee, H.B.; Kiew, L.V.; Chung, L.Y.; Burgess, K. BODIPY dyes in photodynamic therapy. Chem. Soc. Rev. 2013, 42, 77-88. [CrossRef] [PubMed]

57. Bertrand, B.; Passador, K.; Goze, C.; Denat, F.; Bodio, E.; Salmain, M. Metal-based BODIPY derivatives as multimodal tools for life sciences. Coordin. Chem. Rev. 2018, 358, 108-124. [CrossRef]

58. Turksoy, A.; Yildiz, D.; Akkaya, E.U. Photosensitization and controlled photosensitization with BODIPY dyes. Coordin. Chem. Rev. 2019, 379, 47-64. [CrossRef]

59. Kim, T.; Duan, Z.; Talukdar, S.; Lei, C.; Kim, D.; Sessler, J.L.; Sarma, T. Excitonically Coupled Cyclic BF2 Arrays of Calix[8]- and Calix[16]phyrin as Near-IR-Chromophores. Angew. Chem. Int. Ed. 2020. [CrossRef]

60. Ke, X.S.; Kim, T.; Lynch, V.M.; Kim, D.; Sessler, J.L. Flattened Calixarene-like Cyclic BODIPY Array: A New Photosynthetic Antenna Model. J. Am. Chem. Soc. 2017, 139, 13950-13956. [CrossRef] 
61. Ishida, M.; Omagari, T.; Hirosawa, R.; Jono, K.; Sung, Y.M.; Yasutake, Y.; Uno, H.; Toganoh, M.; Nakanotani, H.; Fukatsu, S. Boron Difluoride Complexes of Expanded N-Confused Calix[n]phyrins That Demonstrate Unique Luminescent and Lasing Properties. Angew. Chem. Int. Ed. 2016, 55, 12045-12049. [CrossRef]

62. Zhang, F.; Baudron, S.A.; Hosseini, M.W. Solvent and anion effects on the organization of a luminescent [2+2] BODIPY/Ag(I) metallamacrocycle in the crystalline state. CrystEngComm 2017, 19, 4393-4400. [CrossRef]

63. Chua, M.H.; Kim, T.; Lim, Z.L.; Gopalakrishna, T.Y.; Ni, Y.; Xu, J.; Kim, D.; Wu, J. BODIPY-Based Antiaromatic Macrocycles: Facile Synthesis by Knoevenagel Condensation and Unusual Aggregation-Enhanced Two-Photon Absorption Properties. Chem. Eur. J. 2018, 24, 2232-2241. [CrossRef] [PubMed]

64. Hojo, T.; Nakamura, T.; Matsuoka, R.; Nabeshima, T. Uniquely folded shapes, photophysical properties, and recognition abilities of macrocyclic BODIPY oligomers. Heteroatom Chem. 2018, 29, e21470. [CrossRef]

65. Uchida, J.; Nakamura, T.; Yamamura, M.; Yamaguchi, G.; Nabeshima, T. m-Phenylene-Linked Dipyrrins and Their Boron-Difluoride Complexes as Variously Shaped Macrocyclic Oligomers. Org. Lett. 2016, 18, 5380-5383. [CrossRef] [PubMed]

66. Cha, N.R.; Moon, S.Y.; Chang, S.-K. New ON-OFF type $\mathrm{Ca}^{2+}$-selective fluoroionophore having boron-dipyrromethene fluorophores. Tetrahedron Lett. 2003, 44, 8265-8268. [CrossRef]

67. Kim, H.J.; Kim, J.S. BODIPY appended cone-calix[4]arene: Selective fluorescence changes upon Ca2+ binding. Tetrahedron Lett. 2006, 47, 7051-7055. [CrossRef]

68. Malval, J.-P.; Leray, I.; Valeur, B. A highly selective fluorescent molecular sensor for potassium based on a calix[4]bisazacrown bearing boron-dipyrromethene fluorophores. New J. Chem. 2005, 29, 1089-1094. [CrossRef]

69. Melnikov, P.; Zanoni, L.Z. Clinical Effects of Cesium Intake. Biol. Trace Elem. Res. 2010, 135, 1-9. [CrossRef]

70. Depauw, A.; Kumar, N.; Ha-Thi, M.-H.; Leray, I. Calixarene-Based Fluorescent Sensors for Cesium Cations Containing BODIPY Fluorophore. J. Phys. Chem. A 2015, 11, 6065-6073. [CrossRef]

71. Csokai, V.; Kádár, M.; Ha Mai, D.L.; Varga, O.; Tóth, K.; Kubinyi, M.; Grün, A.; Bitter, I. Synthesis, optical and electroanalytical characterizations of a thiacalix[4](N-phenylazacrown-5)ether-BODIPY ionophore. Tetrahedron 2008, 64, 1058-1063. [CrossRef]

72. Dam, H.H.; Reinhoudt, D.N.; Verboom, W. Multicoordinate ligands for actinide/lanthanide separations. Chem. Soc. Rev. 2007, 36, 367-377. [CrossRef]

73. Bayrakc1, M.; Kursunlu, A.N.; Güler, E.; Ertul, Ş. A new calix[4]azacrown ether based boradiazaindacene (BODIPY): Selective fluorescence changes towards trivalent lanthanide ions. Dyes Pigments 2013, 99, 268-274. [CrossRef]

74. Nolan, E.M.; Lippard, S.J. Tools and tactics for the optical detection of mercuric ion. Chem. Rev. 2008, 108, 3443-3480. [CrossRef] [PubMed]

75. Yu, L.; Li, N. Noble Metal Nanoparticles-Based Colorimetric Biosensor for Visual Quantification: A Mini Review. Chemosensors 2019, 7, 53. [CrossRef]

76. Johnson, A.D.; Curtis, R.M.; Wallace, K.J. Low Molecular Weight Fluorescent Probes (LMFPs) to Detect the Group 12 Metal Triad. Chemosensors 2019, 7, 22. [CrossRef]

77. Sulak, M.; Kursunlu, A.N.; Girgin, B.; Karakuş, Ö.Ö.; Güler, E. A highly selective fluorescent sensor for mercury(II) ion based on BODIPY and Calix[4]arene bearing triazolenaphthylene groups; synthesis and photophysical investigations. J. Photochem. Photobio. A 2017, 349, 129-137. [CrossRef]

78. Hou, J.-T.; Ren, W.X.; Li, K.; Seo, J.; Sharma, A.; Yu, X.-Q.; Kim, J.S. Fluorescent bioimaging of pH: From design to applications. Chem. Soc. Rev. 2017, 46, 2076-2090. [CrossRef]

79. Yue, Y.; Huo, F.; Lee, S.; Yin, C.; Yoon, J. A review: The trend of progress about pH probes in cell application in recent years. Analyst 2017, 142, 30-41. [CrossRef]

80. Méndez-Ardoy, A.; Reina, J.J.; Montenegro, J. Synthesis and Supramolecular Functional Assemblies of Ratiometric pH Probes. Chem. Eur. J. 2020, 26, 7516-7536. [CrossRef]

81. Hammarling, K.; Engholm, M.; Andersson, H.; Sandberg, M.; Nilsson, H.-E. Broad-Range Hydrogel-Based pH Sensor with Capacitive Readout Manufactured on a Flexible Substrate. Chemosensors 2018, 6, 30. [CrossRef]

82. Baki, C.N.; Akkaya, E.U. Boradiazaindacene-Appended Calix[4]arene: Fluorescence Sensing of pH Near Neutrality. J. Org. Chem. 2001, 66, 1512-1513. [CrossRef]

83. Han, F.; Xu, Y.; Jiang, D.; Qin, Y.; Chen, H. A BODIPY-derived fluorescent probe for cellular pH measurements. Anal. Biochem. 2013, 435, 106-113. [CrossRef] [PubMed] 
84. Yang, C.; Liu, T.; Xu, Y.; Qin, Y. Fluorescent ion optodes based on calixarene functionized boron dipyrromethene chromoionophore for simultaneous measurement of multi-electrolytes in biological samples. Sensor. Actuat. B Chem. 2014, 192, 423-428. [CrossRef]

85. Lo, P.-C.; Rodríguez-Morgade, M.S.; Pandey, R.K.; Ng, D.K.P.; Torres, T.; Dumoulin, F. The unique features and promises of phthalocyanines as advanced photosensitisers for photodynamic therapy of cancer. Chem. Soc. Rev. 2020, 49, 1041-1056. [CrossRef] [PubMed]

86. Cakmak, Y.; Nalbantoglu, T.; Durgut, T.; Akkaya, E.U. PEGylated calix[4]arene as a carrier for a BODIPY-based photosensitizer. Tetrahedron Lett. 2014, 55, 538-540. [CrossRef]

87. Tosi, I.; Bardi, B.; Ambrosetti, M.; Domenichini, E.; Iagatti, A.; Baldini, L.; Cappelli, C.; Di Donato, M.; Sansone, F.; Sissa, C.; et al. Investigation of electronic energy transfer in a BODIPY-decorated calix[4]arene. Dyes Pigment. 2019, 171, 107652. [CrossRef]

88. Moran, J.R.; Karbach, S.; Cram, D.J. Cavitands: Synthetic molecular vessels. J. Am. Chem. Soc. 1982, 104, 5826-5828. [CrossRef]

89. Cram, D.J.; Choi, H.J.; Bryant, J.A.; Knobler, C.B. Host-guest complexation. 62. Solvophobic and entropic driving forces for forming velcraplexes, which are 4-fold, lock-key dimers in organic media. J. Am. Chem. Soc. 1992, 114, 7748-7765. [CrossRef]

90. Soncini, P.; Bonsignore, S.; Dalcanale, E.; Ugozzoli, F. Cavitands as versatile molecular receptors. J. Org. Chem. 1992, 57, 4608-4612. [CrossRef]

91. Roncucci, P.; Pirondini, L.; Paderni, G.; Massera, C.; Dalcanale, E.; Azov, V.A.; Diederich, F. Conformational behavior of pyrazine-bridged and mixed-bridged cavitands: A general model for solvent effects on thermal "vase-kite" switching. Chem. Eur. J. 2006, 12, 4775-4784. [CrossRef]

92. Haino, T.; Rudkevich, D.M.; Shivanyuk, A.; Rissanen, K.; Rebek, J. Julius, Induced-Fit Molecular Recognition with Water-Soluble Cavitands. Chem. Eur. J. 2000, 6, 3797-3805. [CrossRef]

93. Skinner, P.J.; Cheetham, A.G.; Beeby, A.; Gramlich, V.; Diederich, F. Conformational Switching of Resorcin[4]arene Cavitands by Protonation, Preliminary Communication. Helv. Chim. Acta 2001, 84, 2146-2153. [CrossRef]

94. Azov, V.; Diederich, F.; Lill, Y.; Hecht, B. Synthesis and Conformational Switching of Partially and Differentially Bridged Resorcin[4]arenes Bearing Fluorescent Dye Labels Preliminary Communication. Helv. Chim. Acta 2003, 86, 2149-2155. [CrossRef]

95. Azov, V.A.; Schlegel, A.; Diederich, F. Geometrically Precisely Defined Multinanometer Expansion/Contraction Motions in a Resorcin[4]arene Cavitand Based Molecular Switch. Angew. Chem. Int. Ed. 2005, 44, 4635-4638. [CrossRef] [PubMed]

96. Azov, V.A.; Schlegel, A.; Diederich, F. Functionalized Calix[4]resorcinarene Cavitands. Versatile Platforms for the Modular Construction of Extended Molecular Switches. Bull. Chem. Soc. Jpn. 2006, 79, 1920-1940. [CrossRef]

97. Pochorovski, I.; Breiten, B.; Schweizer, W.B.; Diederich, F. FRET Studies on a Series of BODIPY-Dye-Labeled Switchable Resorcin[4]arene Cavitands. Chem. Eur. J. 2010, 16, 12590-12602. [CrossRef] [PubMed]

98. Pochorovski, I.; Knehans, T.; Nettels, D.; Müller, A.M.; Schweizer, W.B.; Caflisch, A.; Schuler, B.; Diederich, F. Experimental and Computational Study of BODIPY Dye-Labeled Cavitand Dynamics. J. Am. Chem. Soc. 2014, 136, 2441-2449. [CrossRef]

99. Otto, J.; Wang, L.; Pochorovski, I.; Blau, S.M.; Aspuru-Guzik, A.; Bao, Z.; Engel, G.S.; Chiu, M. Disentanglement of Excited-State Dynamics with Implications for FRET Measurements: Two-Dimensional Electronic Spectroscopy of a BODIPY-Functionalized Cavitand. Chem. Sci. 2018, 9, 3694-3703. [CrossRef]

100. Bastug, E.; Kursunlu, A.N.; Guler, E. A fluorescent clever macrocycle: Deca-BODIPY bearing a pillar[5]arene and its selective binding of asparagine in half-aqueous medium. J. Lumin. 2020, 225, 117343. [CrossRef]

101. Davis, A.V.; Yeh, R.M.; Raymond, K.N. Supramolecular assembly dynamics. Proc. Natl. Acad. Sci. USA 2002, 99, 4793-4796. [CrossRef]

102. Wehner, M.; Würthner, F. Supramolecular polymerization through kinetic pathway control and living chain growth. Nat. Rev. Chem. 2019, 4, 38-53. [CrossRef]

103. Meng, L.-B.; Li, D.; Xiong, S.; Hu, X.-Y.; Wang, L.; Li, G. FRET-capable supramolecular polymers based on a BODIPY-bridged pillar[5]arene dimer with BODIPY guests for mimicking the light-harvesting system of natural photosynthesis. Chem. Commun. 2015, 51, 4643-4646. [CrossRef] [PubMed] 
104. Meng, L.-B.; Zhang, W.; Li, D.; Li, Y.; Hu, X.-Y.; Wang, L.; Li, G. pH-Responsive supramolecular vesicles assembled by water-soluble pillar[5]arene and a BODIPY photosensitizer for chemo-photodynamic dual therapy. Chem. Commun. 2015, 51, 14381-14384. [CrossRef] [PubMed]

105. Mena-Hernando, S.; Perez, E.M. Mechanically interlocked materials. Rotaxanes and catenanes beyond the small molecule. Chem. Soc. Rev. 2019, 48, 5016-5032. [CrossRef] [PubMed]

106. Sun, N.; Xiao, X.; Li, W.; Jiang, J. Multistimuli sensitive behavior of novel BODIPY-involved pillar[5]arene-based fluorescent [2]rotaxane and its supramolecular gel. Adv. Sci. 2015, 2, 1500082. [CrossRef] [PubMed]

107. Aratani, N.; Kim, D.; Osuka, A. Discrete cyclic porphyrin arrays as artificial light-harvesting antenna. Acc. Chem. Res. 2009, 42, 1922-1934. [CrossRef]

108. Miyatake, T.; Tamiaki, H. Self-aggregates of natural chlorophylls and their synthetic analogues in aqueous media for making light-harvesting systems. Coordin. Chem. Rev. 2010, 254, 2593-2602. [CrossRef]

109. Xiao, T.; Zhong, W.; Zhou, L.; Xu, L.; Sun, X.-Q.; Elmes, R.B.P.; Hu, X.-Y.; Wang, L. Artificial light-harvesting systems fabricated by supramolecular host-guest interactions. Chin. Chem. Lett. 2019, 30, 31-36. [CrossRef]

110. Kursunlu, A.N.; Baslak, C. A BODIPY-bearing pillar[5]arene for mimicking photosynthesis: Multi-fluorophoric light harvesting system. Tetrahedron Lett. 2018, 59, 1958-1962. [CrossRef]

(C) 2020 by the authors. Licensee MDPI, Basel, Switzerland. This article is an open access article distributed under the terms and conditions of the Creative Commons Attribution (CC BY) license (http://creativecommons.org/licenses/by/4.0/). 